\title{
Acechando en las sombras. Breve acercamiento a la naturaleza jurídica del director encubierto ${ }^{(*)}$
}

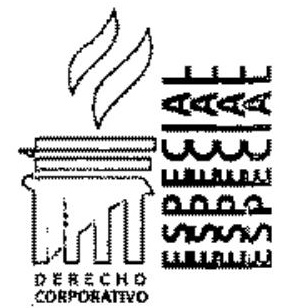

\section{Martin Mayandia Burns}

Abogado por la Universidad de Lima.

SUMARI0:

1. Introducción.

II. Definiendo lo que implixa ser un difector encubierto de una sociedad bajo legislación del common law:

1. Homativa relevante en cuanto a los directores encubiertos;

2. Consideraciones adicionales.

III. Naturafeza juridica de la figura del director encublerto:

1. Persona;

2. Direcclones o instracciones;

3. Miembros del directorio de una sociedad;

4. Costumbre de actuat.

IV. El nexo causal en el marce de la figula del director encubierta.

V. La excepción por asesoraniento de acuerdo con la capacidad profesional o relackion de negocios:

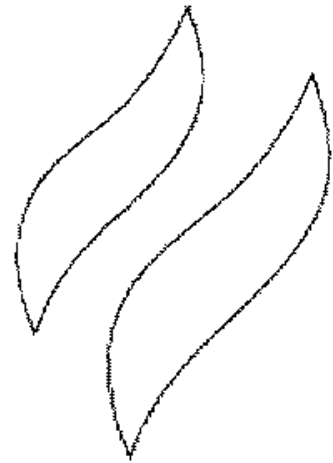

1. Consejo:

2. De conformidad cen los conocimiento o habilidades derivados de la tapacidad profesional.

v. Jurisprudencia del common law - Utraframe (UK) Ltd. vs. Fielding and others.

VI. Implizancias de encontrar a un directer encubierto.

Vill. Defensa de los directores o de los difectores encubiertos.

IX. ¿Quièn puede ser sujeto de responsabilidad a la laz de la figura del director enctbiertol.

x. La figura del director encubierto según la Companies Act 2006.

x. H director entubierto en la doctrina romano-germánita:

1. El administrador oculto en la doctrina española;

2. El administrador oculto o dirertor encubiecto en la doctrina latinoanericana;

3. El director encubierto en la regulación peruana.

xil. Comparación entre la regulación para directores que aplica para los directores encubiertos en el commen law y las respensabilidates bajo la

Ley General de 5ociedades aplicables a directeres.

xill. Conclusiones.

(*) El tema del presente articulo es un extracto de la materia central de la tesis denominada La incorporacion de la figura del director encubierto a la ley 26887 ; Ley General de 5ociedades, elaborada por el autor para optar el títslo de abogado en la facultad de Derecho de la Universidad de Lima. La tesis se puede encontrar en la biblioteca central delatuniversidad de.Lima! 
"Todo el mundo es sabio hasta que habla."

Proverbio irlandés

\section{INTRODUCCIÓN}

Es un hecho bien conocido que la responsabilidad limitada en cuanto a la sociedad anónima es quizás el principio más importante del derecho societario moderno. ${ }^{1}$

Una consecuencia de ello es su diferenciación de las personas que la componen pues, desde el nacimiento de una sociedad, una nueva persona es creada, distinta de aquellas que le dieron vida.

En tal sentido, es importante anotar que las definiciones de lo que es una sociedad, no varian demasiado en las distintas jurisdicciones ${ }^{3}$ donde estas pueden ser creadas.

Se dice que el principio de la responsabilidad limitada tiene su origen y fue firmemente establecido probablemente por primera vez en ef fallo de la House of Lords en Salomon vs. A. Salomon \& Company Ltd. o como se le conoce en los paises de tradición juridica latina "Doctrina de la Personalidad Juridica" $y^{\text {"Doctrina del Velo }}$ Societario" ${ }^{\prime 4}$, fallo que en mayor o menor medida ha sido adoptado por las leyes societarias del orbe, sin hacer expresa y necesaria referencia a dicho caso.

Tal como lo sostiene Eduardo López, el velo societario tiene evidentes beneficios en economias capitalistas y dinámicas, economias a las cuales recientemente se està sumando el Perú a pasos agigantados. La responsabilidad

1 FARRAR, Simeon J, Farrar's Company Law - Third Edition, Butterworths, Londres, 1991, p. 68.

RIPERT, Georges, Aspectos juridicos del capitolismo moderno, Editorial Bosch, Buenos Aires, 1950, p. 215.

Ley General tie Sociedades:

"Articulo 51. Capital y responsabilidad de tos socios

En la sociedad anónima el capital está representado por acciones nominativas y se integra par aportes de los accion. stas, quienes no responden personalmente de las deudas sociales. No se admite el aporte de servicios en la sociedad anónima".

PETIET, Ben, Companylaw-Second Edition, Pearsan Education Limited, Dorchester, 2005, p. 15.

2 Ley General de Sociedades:

"Articulo 6. Personalidad jutidica

La sociedad adquiere personalidad juridica desde su inscripcion en el Registro y ta mantiene hasta que se inscribe su extincion"

3 Companies Act 1985 de inglaterra:

"13(3) From the day of the incorporation mentioned in the certificate, the subscribers of the memorandum, together with such other persons as may from time ro time become members of the company, shall be a body corporote by the name contoined in the memorandum".

13(3) Desde el dia del registro que se menciona en el certificado, los suscriptores del memorádum (pacto social y estat. uto de acuerdo con la Ley General de Sociedades), junto con aquellos personas que de tiempo en fiempo se conviertar en socios de la sociedad, se convertión en una persona juridica de acueto con el nombre contenido en el memorín. dum.

Corporation Law de Australia:

"(2) A company comes into existence as a body corporare at the beginning day of the day on which it is registared".

(2) Una sociedad se convierte en persona juridica a partir det dia en alse se registra como tat.

4 El Leading Case denominato Salomon v5. A. Satomon \& Company Lid. [1897] AC 22 fue resuelto por la House of tords en 189 ?

Este tiene una doble implicancia en el derecho societario ingtes primordiamente y en general era derecho 50 . cietario porque: (i) aceptó la existencia de la sociedad de una sola persona (oneman companyl; (ii) pero principalmente, porque este fallo estableció firmemente el concepto de la personalidad jufitica separada e independiente de las sociedades con una responsabilidad limitada de los socios que la componen (J. FARRAR, Simeon, Op. Cit, p. 70 .

Este falo fue duramente criticado desde su publicación, en tanto se consideraba cue habia llegado demasiado iejos. El comentatio de la Law Quaterly Review de 1897 tue que la House of Lords habia adimitido que un comerci. 
limitada fomenta la creación de empresas en tanto que promueve la inversión en empresas potencialmente productivas pero cargadas de incertidumbre. 5
Sin embargo, es evidente que los beneficios de la responsabilidad limitada deben ser balanceados con los costos de la misma. ${ }^{6}$ Solo por citar un ejemplo, es el casodel acreedor que le otorga un crédito

ante individual y sels marionetas eran șficientes y que los requisitos legales eran una mera maquinaria U. FARRAR, Simeon, Op. Cit, p. 72).

A partir de este fallo, la teoria del velo societario se aplicó como principio general, salvo que aparecieran cifcunstancias que determinaran lo contrario, lo que determinó a su vez el nacimiento de la "Doctrina del levantamiento del velo societario" (MISPIRETA GALVEZ, Callos Alberto, El allanomiento de la personalidad juridica o levantamiento del velo societario. En: Tratado de Derecho Mercantil, Tomo I, Lima, Gaceta Juridica, 2003, p. 97).

La teoria del "Allanamiento de la personalidad juridica" señala que cuando el velo societario es utilizado con propósitos deshonestos, ilicitos, con el fin de defratuar, el deracho societario tiende a considerar que el velo societario no existe desarroltando dos vertientes al respecto dependiendo de cada caso en particular: (i) que la sociedad no es mas que una agiupación de personas fisicas por eiemplo en Walkovszky vs. Carlton (J. FARRAR, Simeon, Op. Cit., p. 80); y (ii) que la sociedad cuyo velo societario es levantado es parte de una sociedad mas grande, la cual se disgrega en varias sociedades mas pequeñas a efectos de limitar la responsabilidad en la sociedad pequef́a afectada como por ejemplo en Carte Btanche (Singapore) Pte, Ltd. vs. Diners Clublnternational Inc, (CARYWillam L. and EISEMBERG, Melvin Aron, Cases and material on Corporations - Seventh Edition, The Foundation Press Inc, New York, 1995, $p .174)$.

5 Sin perjuicio de las conocidas ventajas económicas de la responsabilidad limitada, tema que va mas alta de los akances de esta tesis, no está de más dexir que existen un sinnumero de ventajas adicionales provenientes de la responsabilidad limitada, siendo la principal, la transferencia del riesgo de quiebra de los accionistas de la sociedad a los acreedores de esta, asi lo detalla LOPEZ SANDOVAL, Eduardo, Materioles para el curso de Finanzos Corporarivas de la Universidad de Lima, Lima, 2006, a saber:

Fomento de la actividad empresatial en tanto que limita los riesgos inherentes al manejo de un negocio, salvo que el acreedor pida garantias adicionales las cuales el deudor está en potestad de otorgar.

Fomento de la inversión pasiva: Es aquella que realizada sobre la base que el inversionista no jugará un papel ên la administración de una sociedad. El argumento radica en que para que la inversión florezca debe existiz, necesariamente, un tope maximo de responsabilidad, de lo contrapio, el rlesgo seria, sino incalculable, demasiado alto como para que la sociedad pueda afrontar el rendimiento esperado por ei inversionista para asumir ese riesgo.

Diversificación del portafolio. La responsabilidad limitada permite la diversificación de portafolio, entendida esta como el proceso por el cual un inversionista puede reducir los riesgos especificos (no sistèmicos) de daterminados valores riesgosos, mediante la inversión en otros valores de menor resgo y consecuentemente de menor rendimiento. El costo de financiación via capital sera extremadamente alto en caso no existiera responsabilidad limitada, puesto que las sociedades se verian en la obilgación de ofrecer un rendimiento que compense tanto el riesgo sistémico como el riesgo especifico de cada atción

Costo de Capital: El costo de capital de una sociedad está dado por el rendimiento requerido por sus proveedores ce fondos, sean ac reedores $o$ accionistas.

Responsabilidad imitada versus costo de capital: Es to implica que los costos de evaluacion crediticia de cada accionista hacen que este sistema sea poco atractivo. La respons abilidad limitada reduce los costos de transacción, en tanto los acreedores solo requieren efectuar una sola evaluación crediticia sobre un único obligado: la sociedad. A menor incertidumbre menor riesgo.

Transferibilidad de las acciones: Si existiese la responsabilidad limitada, los inversionistas tendrian un interes marcado en conocer quienes son los otros accionistas de la sociedad, dado que eso resultaria relevante para calcular el riesgo de su inversión. Esto supondria grandes costos de información y monitoreo de la riqueza de los otros inversionistas. Esto implicaria a su vez el impulso a las restricciones a la transmisibilidad de acciones para aseguraz que quien compra sea tan solvente como quien vende En consecuencia el precio de las acciones no sería uniforme, lo que a su vez acarrearia la inexistencia del mercado de valores como lo conocemos.

Responsabilidad extracontractual: Los accionistas están protegidos contra eventos que originen responsabilidad extracontractuat.

6 Es un hecho que la separación de la sociedad del inversionista détrás de ella, proveyó el impulso esencial dezràs de los más importantes emprendimientos del siglo. Aunque muchos de ellos fracasaron, la sociedad en general con sidera como un fin más valioso los logros adquiridos mediante estos emprendimientos que en general al conjunto de pérdidas generadas por las insolvenclas y liquidaciones. Sin embazgo, socialmente es aborzecida la persecución de fines ilicitos a través de las sociedades, siendo la persecución de estas actitudés ilicitas la que da nacimiento a doctrinas como la del "Levantamiento del Velo Societazio". 
ala sociedad y que con posterioridad se encuentra con que no lo puede cobrar por supuestos de quiebra, insolvencia o conductas ilicitas por parte de los que administran dicha sociedad.

Aún cuando el fallo en el caso Salomon vs. A. Salomon \& Company Ltd ha sido criticado, iconsiderándosele -entre otras cosas- de "calamitoso" ${ }^{\prime \prime}$, la doctrina creada alrededor de este caso emblemático ha sido aplicada subsecuentemente sin mayores variaciones, casi inflexiblemente.

No obstante, se ha reconocido que tal inflexibilidad ha acarreado consecuencias indeseables. Se ha reconocido asimismo que los principios de asunción de riesgo consagrados en Solomon vs. A Salomon \& Company Ltd. olas Doctrinas de la Personalidad Juridica y del Velo Societario no son siempre y necesariamente las más apropiadas $^{7} y_{\text {, en tal sentido }}$ las leyes y los fallos han sabido distinguir entre los riesgos legítimos (de acuerdo con el giro del negocio y el leal saber y entender de aquel que lo administra) y aquel riesgo en el cual el administrador de la sociedad incurre llegitimamente. ${ }^{8}$

Consecuentemente, dada la posición de poder de los administradores, en detrimento de la po. sicion de los socios y acreedores en la sociedad, el raciocinio jurídico general ha discurrido hacia el aumento de las responsabilidades y obligaciones de los directores y administradores de la sociedad, y en general de cualquier persona envuelta en su manejo. Asi, consideramos importante resaltar lo señalado por el Juez inglès Onley en la exposicion de motivos que hizo para el fallo de Chew vs. NCSC (No. 2)\%:
"Crear leyes relacionadas con sociedades y aquellas personas que se encuentran involucradas en sucreacion y administracion, podria ser descrito, como una de las industrias de mayor crecimiento actualmente. Considero ademas que es justo decir, sin embargo, que desde la introduccion del concepto de responsabilidad limitada en las sociedades, tambièn ha aumentado el potencial parausar tal concepto a través de estas sociedades con fines ilicitos y de defraudación de aquel que es cándido o codicioso. Consecuentemente, la ley ha debido hacerse cada vez más compleja con el objeto de mitigar estos daños, a tal extremo, que pocos, si alguno, pueden decir honestamente que tiene un completo entendimiento de todas las regulaciones aplicables a las sociedades. Estando asi las cosas, un tema que prevalece a través de esta compleja estructura, es que, aquellos en la situacion de tomar ventaja de suposición de dominio en la administracion y gerenciamiento de una sociedad, siempre deberán actuar con el máximo cuidado, diligencia y honestidad, de tal forma que, no tomen ventaja injusta de aquellos que estan menos informados de la situocion de tal sociedad. 10

Con el objeto de proteger el interés de los socios y los acreedores (asi como de lograr que las sociedades actuen en concordancia con el orden público y las buenas costumbres), la ley le otorga a los directores de la sociedad debe. res fiduciarios estrictos, como en el caso de la legislación peruana que recoge dichos deberes generales en el articulo 171 de la Ley General de Sociedades. ${ }^{11}$

7 El Juez Supremo Rogers de la Corte Suprema de New South Wales, Australia senalo, con relacion a un caso presentado ante su corte que:

"La separacion proporcionada por la doctrina del velo societario deberia ser reexaminada a ta fuz de los modernos controtos comerciales y de tos grupos de sociedades".

8 Revisar entre otros la regla del "correcto luicio empresaral" (business judgement rule l, que detemina en jurssdicciones del common faw què decisiones riesgosas son validas y cuales no lo son.

9 [1985?3A.C.L.C. 212.

10 [1985] 3 A.C.L.C. 212. Paràgrafo No. 218 \{la traducción es nuestra).

11 Ley General de Sociedades:

"Artitulo 171.- Ejercicio del cargo y reserva

Los directores desempeñan el cargo con la diligencia de un ordenado comerciante y de un representante feal. Estan obligados a guardar reserva respecto de los negocios de la socisdad y de la informacion social a que tengat acce. so, aun despuès de cesar en sus funciones". 
Tales deberes fiduciarios normalmente se ven reforzados por responsabilidades contenidas en las antes mencionadas leyes societarias y en los estatutos de cada sociedad. Es así que una de las principales preocupaciones de los directores de las sociedades, son las potenciales responsabilidades que se desencadenan para estos en el supuesto de ruptura de alguna de sus obligaciones como tales. ${ }^{12}$

La ley impone sanciones severas a aquellos directores que violan sus deberes fiduciarios y estatutarios. Asimismo también en ciertas jurisdicciones existen consecuencias graves para aquellos directores que son descalificados como tales. ${ }^{13}$

Esta descalificación, no debe confundirse con los impedimentos ${ }^{14}$ contemplados en la Ley General de Sociedades del Perú para ejercer el cargo de director. En tal sentido, mientras que el impedimento supone una condición ex ante, por la cual la persona no es elegible para ocupar el cargo de director, la descalificación implica que la personia fue nombrada como director les decir no se encontraba inmersa en ningùn impedimento) pero que consecuencia de una actuación ilícita, es sancionada con esta medida (la descalificación) la cual impide que en el futuro ejerza el cargo de director.

\section{DEFINIENOO LO QUE IMPLICA SER UN DI- RECTOR ENCUBIERTO OE UNA SOCIEDAO BAJO LEGISLACIÓN OEL COMMON LAW}

\section{Normativa relevante en cuanto a los directores encubiertos}

Asi, mültiples leyes societarias ${ }^{15}$ han extendido (principalmente en jurisdicciones del common $(a w)^{16}$ la definición o los alcances de aquella persona que entienden como director para incluir no solo a los directores vallidamente escogidos para la administración de una sociedad o directores de jure, ${ }^{17}$ sino tambien para alcanzar a personas a las cuales la ley ha reconocido que

12 Supuestos analizados en otro lugar del presente trabajo.

13 La descalificación como tal no existe en jułlsdicción peruana, si se quisiera hacer un simil, para obtener el efecto mas cercano, uno debera remitirse a la "Ley General del Sistema Concursal; Ley 27809", la cual en el inciso b) de su articulo 100 señala entre otras cosas que el quebrado mientras dure su estado está impedido de ejercer el cargo de director, gerente entre otros, por el periodo que dure la situación declarada de quebrado.

14 Ley General de Sociedades:

"Articulo 161.--Impedimentos

No pueden ser directores:

Los incapaces;

Los quebrados;

Los que por razón de su cargo o funciones esten impedidos de ejercer el comercio;

Los funcionarios y Servidores Públicos, que presten servicios en entidades públicas cuyas funciones estuvieran diractamente vinculadas al sector economico en el que la sociedad desarrolla su actividad empresarial, salvo que representen la participacion del Estado en dichas sociedades.

Los que tengan pleito pendiente con la sociedad en catidad de demandantes o estén sujetos a acción sociol de responsa. bilidad iniciada por la sociedad y los que estèn impedidos por mandato de una medida cautelar dictada por la autoridad judicial o arbitral;y,

Los que sean directores, administradores, representantes legales o apoderados de sociedades o socios de sociedades de personas que tuvieran en foma permanente intereses opuestos a los de la sociedad o que personaimente tengan con ella oposición permanente".

15 Como se ha señalado en anteriores oportunidades, cuando nos refizamos a leyes societarias en general, deberemos entender que nos encontramos ante leyes que regulan el manejo de las sociedades constituidas en una jurisdicción en particular y que se puedan entender como similes de la Ley General de Sociedades peruana.

16 Entre las que hemos podido analizar se encuentran Inglaterra, Australia, Nueva Zelanda, Irlanda.

17 MARKOVIC, Michael, The Law of Shadow Directorship. En: Australian Journal of Corporote Law, Sydney, No. 6, p. 323. Markovic señala que segün la regulación del common law se entiende como director de jure a aquel que ha sido validamente nombrado bajo la ley que regula a la sociedad y al estatuto de la mlsma.

En jurisdicción peruana se entiende como director de jure a aquel que ha sido elegido en principio de acuerdo con 
deben ser tratadas como directores en lo que concierne a los asuntos de una sociedad. "Se encuentra en esta linea la Companies Act 1985 de inglatera. ${ }^{12}$

Es asi como la sección 741. de la Companies Act 1985, cual es la norma inglesa que regirá la figura del director y la del director encubierto hasta enero de 2009 , señala que, la palabra"director" incluye a cualquier persona que ocupe la posición de director, bajo cualquier denominación o nombre.

Continua señalando que deberà entenderse como "director encubierto" a las personas en concordancia con cuyas direcciones o instruc" ciones los directores de una sociedad estan acostumbrados a actuar.

Por otro lado, es clara la norma al hacer una excepción categónica, estableciendo que una persona no puede ser señalada como director encubierto, sólo porque los directores actúen de conformidad con el consejo o asesoria prestado por ella de conformidad con los conocimientos o habilidades derivados de su capacidad profesional.

Establece la seccion 741. las secciones de la propia norma en virtud de las cuales una director encubierto deberá ser tratado como un director de la sociedad, estas son: (i) La sección 309., la cual versa sobre la responsabilidad de los directores y su deber de preocuparse por los intereses de los empleados; (ii) la sección 319. la cual discurre sobre los directores y las provisiones sobre los contratos de trabajo a largo plazo; (iii) las secciones 320. a 322., las cuales establecen las disposiciones aplicables a las transacciones de propiedad sustanciales de la sociedad que involucren a los directores; (iv) la sección 322B., la cual explica las disposiciones relativas a los contratos con accionistas unicos que a la vez son directores; $y$ (v) las secciones 330 . a 346 . las cuales estatuyen las restricciones generales a las sociedades para hacer prestamos entre otros, a directores y otros relacionados con ellos. Estas secciones no son materia del presente trabajo por cuanto lo haria demasiado extenso.

Concluye la misma sección señalando que, en principio, una sociedad no puede ser tratada como director encubier to de ninguna de sus 50 ciedades subsidiarias solo porque los directores de la sociedad subsidiaria estan acostumbrados a actuar en concordancia con las direcciones o instrucciones impartidas por la matriz.

En tal sentido, siendo la Companies Act 1985 la norma primigenia, normas como la Corporation

lo contemplado pon el anticuto 153 de la Ley Genezal de Sociedades, a saber:

Ley General de Sociedades:

"Articulo 153.- Organo colegiado y elección

El directorio es organo colegiado elegido por la junta general (...).

18 Debiendose entender por estos, a los directores de facto y a las directores encubiertos de una sociedad.

19 Componies Act 1985 de Inglaterra:

"7A1. "Director" and "shadow ditertor".

(1) In this Act, "director" includes any person occupying the position of director, by whatever name colled.

(2) in relation to a company, "shadow director" means a person in accordance with whose directions or instructions the directors of the compony are accustomed to act.

However, a person is not deemed a shadow director by reason only that the directors act on advice given by him in a professionalcapacity

(3) For the purposes of the following provisions of this Act, namely.'." section 309 (directors' duty to have regard to interests of employees), section 319 (ditector' long term labor agreements)

section 320 to 322 (substantial property transactions involving directors) section 3228 (contracts with sole members who are directors), and section 330 to 346 general restrictions on power of companies to make loans, efc., to directors and other connected with theml,

(being provisions under which shadow directors are treated as directors), a body corporate is nor to be trealed as a shodow director of any of its sibsidiary companies by reason only that the directors of any of the subsidiary are accustomed to act in accordance with its directions or instructions". 
Law de Australia, la Companies Act 1993 de Nueva Zelanda y la Companies Act 1990 de Irlanda siguieron su misma linea de pensamiento y desarrollo lógico, siendo la Companies Act 1990 de Irlanda la que tiene un desarrollo lógico mas detallado y conciso. ${ }^{20}$

\section{Cansideraciones adicianales}

Después de haber explicado la definicion gem neral de director encubierto recogidas en diferentes paises del Common Law con algunos matices, es nuestra opinión que, sin perjuicio de la tècnica que se utilice para la redacción de normas, las definiciones procedentes de jurisdicciones del Common Law señaladas en su oportunidad, salvo la de Irlanda, coinciden en señalar como director a cualquier persona que actue o se comporte como director, no Importando la denominación que el cargo reciba.

Ahora bien y como se desprende de párrafos anteriores, la figura del director y el director encubierto están normalmente definidas en de manera conjunta, esto responde, a que, bajo jurisdicción del Common Law, es director quien se comporta como tal, restándole su normativa importancia a la designación formal y primando los hechos y en esto consideramos radica el gran avance en su regulación societaria.

Por citar un ejemplo que puede clarificar la situación, estrictamente hablando, el Corporation
Law de Australia no define exactamente lo que se debe entender por director. ${ }^{21}$

Sin embargo, la Sección 60(1) de la antes mencionada norma, señala a algunas personas que deberan ser consideradas directores, en tal sentido tal sección contempla una definición enunciativa sobre quien es un director, dejando abierta la posibilidad que más personas calcen dentro de la definción, según que de los hechos se compruebe que actúan como directores de la sociedad no importando la denominación de su cargo. ${ }^{72}$ Esta característica es compartida por las demás definiciones analizadas sobre lo que es o entienden en jurisdicciones del Common Law como director de una sociedad.

El concepto de director encubierto, tal y como se señala en las distintas definiciones recogidas en este trabajo, es de larga data en la historia de las Companies Laws de Inglaterra. ${ }^{23}$ Más aún, una provisión de estas caracteristicas, se encuentra comprendida en todas las Companies Acts de los distintos paises regulados por el Common Law a los que hemos tenido acceso (de forma directa o indirecta), salvo por los Estados Unidos de Norteamérica.

De las definiciones arriba explicadas se desprende que el director encubierto es aquella persona natural o jurídica que, sin figurar como director de la sociedad, permaneciendo al acecho, des-

20 Para mayores referencias se pueden revisar las siguientes normas:

Secciòn 60. de la Corporation Low de Australia.

Sección 126 . de la Companies Act 1993 de Nueva Zelanda.

Sección 27. de la Companies Act 1990 de Irlanda.

21 MARKOVC, Michael, Op. Cit., p. 324.

22 FERRAN, Eil\$s, Company law and corporate finance, Oxford University Press, Oxford, 1999, p. 482.

23 MARKOVIC, Michael, Op. Cit., p. 326, cita a su vez al Juez Millet, quien es Juez de primera instancia en casos de insolvencias y quiebras en Londres, quien seh̆ala en Shadow directorship a real or imagined threat to Banks. En: Insolvency Practitioner No. 14, Londzes, 1991, p. 14, que definiciones que cuentan con el tenor siguiente: "Un persona bajo ayyas direcciones o instrucciones los directores de una junta o directorio esten acostumbrados a actuar", han aparecldo en las Companies Acts de Inglaterra desde aquella de 1929, sin pezjuicio que no se les definieza como directores encubiertos. Sin embargo es a partir de 1985, como senalazamos anteriormente, que tal figura recibe el nombre con la cual la conocemos ahora. En la actualidad podemos reconocer definiciones muy similares a la usada por el Juez Millet en, por lo pronto, la definición de director encubiezto del Companies Act 1985 de Inglaterra, el Corporation Law de Australia y en el Componies AC 1990 de Irtanda, tres nozmas citadas con anterioridad en este trabajo. 
pliega su influencia sobre la administración de los asuntos de esta. ${ }^{24}$

Claramente, quien desee tener injerencia en los asuntos de una sociedad, debe conducirse de acuerdo con los estándares de conducta espera. dos para un director de tal sociedad (sean estos estandares legales o estatutarios). ${ }^{25}$

Evidentemente, màs allà de la naturaleza explicativa de tales definiciones, existe en las jurisdicciones donde es aplicada, a nivel juris. prudencial, cierta incertidumbre. ${ }^{26}$

Lo anterior, sin perjuicio que los directores de facto ${ }^{27}$ saldrán a la luz, traicionados por su pro" pia conducta frente a la sociedad y terceros, y en tal sentido, ${ }^{28}$ seràn tratados de acuerdo con la naturaleza de sus acciones.

Asi, a diferencia del director de facto, la identificación de un director encubierto resulta ser pues una tarea ardua, esto debido a que en principio como ya su nombre lo indica es un director en la sombra y su intención es perma* necer en ella.

Sin perjuicio de encontrarse regulada por la le" gislación societaria, el concepto de director en- cubierto, no ha sido objeto de consideraciones legales de envergadura hasta tiempos recientes, en las que la dinámica económica ha vuelto mas refinado el manejo de las sociedades.

Otro tema que impidió la adecuada identificación de los directores encubiertos fue la falta de guia jurisprudencial, acerca del tratamiento de la figura en jurisdicciones donde esta ya se contemplaba. ${ }^{29}$

Finalmente, recientes fallos en jurisdicciones como las de inglaterra, Australia, Nueva Zelanda y Singapur han aportado luz de manera sustancial ${ }^{30}$

\section{NATURALEZA JURÍDICA OE LA FIGURA DEL DIRECTOR ENCUBIERTO}

En este punto, habiendo señalado brevemente lo que implica ser un director encubierto y habiendo hecho algunas precisiones preliminares, se hace necesario delimitar los alcances de la figura objeto de este proyecto, a fin de poder continuar su estudio sobre bases más sòlidas.

Para ello, hemos considerado pertinente señalar y explicar los elementos que, articulados co"

$24 \mathrm{KOH}$, Pearle, Shodow director, shadow director, who are thou? En: Singapore Company and Securities Law Journal, Singapore, Volume 14, 1996, p. 340.

25 PASCUTTO, Ermanno y IORDAN, Cally, Review of the Hong Kong companios ordinance ... Consultancy report, MeGill University, Montreal, 1997, p. 132.

26 FIEDLER, Peter, Banks as shadow drectors. En: Jounal of intemational Banking law, $3^{\text {rd }}$ Edition London, 1992, p. 97.

$27 \mathrm{Sin}$ perjuicio que la figura del difector de facto no es parte de esta tesis, es importante mencionarla con el objeco de desindar las figuzas, asi como para puntualizar que es plausible que un director encubierto se convierta en un director de facto. Es asi que un director de facto es aquella persona que realiza las funciones de un director de acuerdo con el Companies Law de Inglatera, pero que no ha sido formalmente nombrado como birector. la Corte Superior puntualizo en Ultraframe (UK) t.td. vs. Fielding and others que "un director de facto es aquella persona que asume funciones que probablemente solo le competen a un directory gue asimismo esta persona tiene la habilidad para lograr participar del proceso de toma de decisiones en una sociedad".

El director de facto tiene hacia la sociedad los mismos deberes como un director debidamente nombrado, en tal sentido es sujeto de todas las responsabilidades legales y estatutarias para con una tociedad además de vener dem beres fiduciarios para con esta.

$28 \mathrm{KOH}$, Pearlie, Op. Cit.. p. 340.

29 CARBOLL, Robin, Shadow dirextor and other third party liability for corporate activity. En: Corporate governance and the duties of compony directors, Centze of comporate law and securities regulation factilly of law - The University of Melbourne, Melboume, 1997, p. 163.

30 MARKOVIC, Michael, Op. Cit., p 325. 
rrectamente, permiten reconocer a un director encubierto.

Asi, de la doctrina del common law se desprende a priori que los elementos para la identificacion de un director encubierto son cuatro, a saber, persona; direcciones o instrucciones; miembros del directorio; costumbre de actuar. ${ }^{31}$

\section{Persona}

El primer elemento de cualquier regulación de director encubierto, es que debe haber una "persona"." Es evidente entonces que de acuerdo con la regulación internacional la definición de persona debe incluir entonces a sociedades. Sin embargo, si una sociedad debe o no ser considerada como director encubierto es un tema contencioso que levantaria no poca polèmica, ${ }^{33}$ Sin embargo en este punto no es ocioso pensar que el objeto subyacente de la norma es que las sociedades también sean responsables por sus acciones (por lo menos las de caracter económico). En el caso de ciertas jurisdicciones como la de Australia la aplicación de la figura del director encubierto estuvo en principio limitada por el Corporate Law solo a la persona natural, posteriormente esta tendencia fue corregida jurisprudencialmente como señalaremos líneas màs abajo, sin embargo hay otras jurisdicciones que tambièn admiten, en la norma positiva, que tal figura recaiga en las personas jurídicas.

Sin perjuicio de lo anterior, si la figura del director encubierto es o no solo de aplicación a las personas naturales, no implica un problema relevante. Pues por su naturaleza, los directores encubiertos no son designados para el cargo de directores de una sociedad.

Consecuentemente, que la regulación societarla de un pais no permita que una persona juridica o sociedad sea director de otra persona juridica o sociedad, como es el caso de la Sección 221 (3) del Companies Law de Australia y el Articulo 160 de la Ley General de Sociedades del Perú, bajo los alcances de una regulación (cualquiera sea esta) de director encubierto, se podria hacer responsable bajo tal figura a una persona juridica o sociedad, tan es asi que tal regulación se viene aplicando efectivamente en Australia, como es el caso del fallo Standard Chartered Bank of Australia Ltd. vs. Antico, donde el Juez Hodgson, señaló que Pioneer Internacional Lid. era un director encubierto de Giant Resources $L t_{d}{ }^{34}$

\section{Direcciones o instrucciones}

El segundo elemento de este análisis, implica que la persona de "direcciones o instrucciones ${ }^{\prime 35}$ lo cual además denota poca

31 DAVIS, Paul L, Gower's - Principles of modern company law; Sixth Edition, Sweet \& Maxwell, London, 1997, p. 182

32 CARROLL, Robin, Op. Cit., p. 169.

Por ejemplo las Secciones 9 y 85 A de la Corporation Law de Australia definen "persona" como un órgano societario, una sociedad, asl como una persona natural ("a body politic o corporote as well as an individual").

33 Por lo menos del analisis que hemos realizado entendemos que es mas eficiente asi, es decir que las sociedades es" tén comprendidas dentro de la posibilidad de ser señaladas como difectores encubiertos, con lo que para el efecto deberá la normativa contener la posibilidad de que tales personas sean señaladas como directores de la sociedad para los efectos de la regulación de director encubierto, aunque solo sea como directores de facto.

Es ast como si bien en juriśdicciones como la de Australia (tal cual en el Peru) una sociedad no puede ser señalada como director de jure de una sociedad, si lo puede ser de facto.

34 Sin perjuicio que solo en Standard Chartered Bank of Australia Ltd. vs. Antico el fuez señalo que una sociedad debla ser considerada como director encubierto de otra, en los demás casos apuntados, ningún Juez negó täl posibilidad.

35 MARKOVIC, Michael, Op. Cit., p. 331 . 
distinción entre una y la otra ${ }^{36}$ para lo cual uno deberá usar el diccionario ${ }^{37}$, sin embargo puede hacerse una diferencia con la palabra "consejo" también reseñada oportunamente. ${ }^{3 .}$ Se sugiere que "direcciones o instrucciones" implica un elemento de compulsión, que el receptor de tales "direcciones o instrucciones" no ejerce discreción decisoria alguna en el proceso de toma de decisiones.

En este punto, no existe consenso en la jurisprudencia. Si bien en jurisdicción inglesa el tema no ha sido tocado directamente, el Juez Millet in Re Hydrodam (Corby) Ltd. sugiere que el supuesto director encubierto debe necesariamente impartir direcciones o instrucciones antes que sea señalado como tal. ${ }^{39}$

La proposición del párrafo anterior es refrendada en jurisdicción neozelandesa por el fallo del Juez Thomas en el caso de Dairy Containers Lto. vs. NZDI Bank Ltd., dado que dicho Juez señala que sin perjuicio que todos los directores del supuesto director encubierto eran sus empleados, la figura del director encubierto no se produjo. El Juez Thomas declaro:
"Como sus empleados, New Zeland Dairy Board delegó en ellos (los directores) la responsabilidad de manejar la sociedad en el mejor interes de los accionistas (New Zeland Dairy Board). Pero no les dio direcciones o instrucciones determinables sobre las acciones que debian tomar ante cada situación o algunas de ellas.,AO

En contraste con esto, la decisión en el caso Australian Securities Commission vs. AS Nominees, reconoce que las direcciones o instrucciones no son necesariamente imprescindibles para constituir la figura del director encubierto. En tal sentido, señala que:

"Haber descubierto esto lque el señor Windsor es director de AS Nominees Ltd. y Ample Funds Ltd. bajo los alcances de la Sección 60 de la Companies Law-de Australia - Ien miopinion. no requiere que se demuestre para este caso en particular que direcciones o instrucciones formales, claramente individualizables, fueron dadas en los asuntos en los que el señor Windsor participó el mismo. Las direcciones o instrucciones formales no son siempre ne-

36 MAYSON, Stephen, EENCH, Derek y otros, Mayson, French and Ryan on Company Law- Twenty First Edition, Oxford University Pre55, Oxford, 2005, p. 463.

37 Diccionario de la Real Academia de la Leņ̧a Española: "Direccion (Del lat directio, ōnis\}.

1. f. Acción y efecto de cirigir.

2. f. Tendencia de algo inmateriat hacia determinados fines. $(\ldots)^{n}$

"Dirigir. (Del lat dirigère).

(..)

4. tr. Encaminar la intención y las operaciones a determinado fin.

5. tr. Gobernar, regit, dar reglas para el manejo de una dependencia, empresa opretension.

6. tr. Aconsejar y gobernar la conciencia de alguien. (...)"

"instrucción. (Dellat. instructio, - onis).

f. Accion de instruir.

(...)

4. f. Conjunto de reglas o advertencias para algün fin. (...)".

38 Diccionario de la Real Academia de la Lengua Española:

"Consejo. (Del lat. consifium).

1. m. Parecer o dictamen que se da o toma para hacer o no hacer algo".

$39 \mathrm{KOH}$, Pearlie, Op. Cit. p. 339 . Senala que es muy probable que en ta práctica se encuentre que los directores ejecutivos de una sociedad matriz, hayan de tiempo en tiempo comunicudo directones a instrucciones a los directores de las sub. sidiarias de esta y consecuentemente se hayan convertido en personalnente responsables bojo la figura de un director encubierto": [1994] B.C.C. 161 en 164.

40 [1995] 7 N.Z.C.L.C. 96,669;[1995] 13 A.C.L.C. 3211. 
cesarias para asegurar que se cumplan los designios buscados. Por tal motivo, no existe razón para constreñir la Sección 60 del Companies Law -de Australia-, denegando esta posibilidad". ${ }^{n 1}$

El tema no deja de ser controvertido, sin embargo consideramos que seria poco coherente no permitir que en una situación de excepción como esta no se pueda aplicar una norma de manera extensiva, de tal forma que se logre generar mayor seguridad juridica. Asimismo es necesario en cualquier situación analizar el tema caso por caso.

\section{Miembros del directorio de una sociedad}

El tercer elemento a ser analizado y que pertenece a todas las jurisdicciones donde se regula esta materia es que los miembros del directorio estèn acostumbrados a actuar en concordancia con las direcciones o instrucciones de otra persona.

Mientras que es evidente que los directores pertenecen necesariamente al directorio de una sociedad, no ha quedado claramente establecido en las distintas jurisdicciones cuál es el número apropiado de directores que deben estar bajo el control de un tercero para que se dé la figura del director encubierto y los fallos de pais a pais han sido contradictorios.

En ese sentido, el fallo de Lord Lowry para el caso Kuwait Asia BankE.C. vs. National Mutual Life Nominees $L$ td. señalaba que "todos los miembros del directorio deben estar acostumbrados a actuar en concordancia con las direcciones o instrucciones de la persona que las comunica." ${ }^{32}$

Finalmente, con el objeto de ser enérgicos, requerir que la totalidad de los miembros del directorio abandonen sus responsabilidades para con la sociedad y se acostumbren a actuar bajo las direcciones o instrucciones de un tercero, seria ignorar el propósito de cualquier regulación relacionada con los directores encubiertos permitiendo una abertura sustancial en la regulación, por lo que en cualquier caso consideramos que bastará la mayoria de los miembros del directorio para que se pueda delimitar claramente la figura del director encubierto.

\section{Costumbre de actuar}

El cuarto elemento a ser analizado para regular la figura del director encubierto, es el elemento "acostumbrado a actuar" o la "costumbre de actuar" es decir la que crea un patrón de conducta, en concordancia con las direcciones o instrucciones de un tercero.

Si bien cierta incertidumbre rodea las palabras "acostumbrado a actuar" $y$ "direcciones o instrucciones", tambièn es cierto que la jurisprudencia estudiada nos brindará considerables lineamientos sobre su interpretación. ${ }^{43}$

Las palabras "acostumbrado a actuar" en conjunción con "direcciones o instrucciones" indican la necesidad de una relación fluida entre las partes involucradas y parece ser que así ha sido aceptado en general por la doctrina y la jurisprudencia. ${ }^{44}$

Sin embargo existe una divergencia de opinión en cuanto a la naturaleza de la relación, en tal sentido, en Re Hydrodam (Corby) Ltd. el Juez Millet señaló en su fallo:

"Lo que se necesita primero es un directorio que pretende o aparenta que actúa con independencia; segundo, un patrón de conducta en el que el directorio lo la mayoria necesaria de este para tomar una decisión social) no

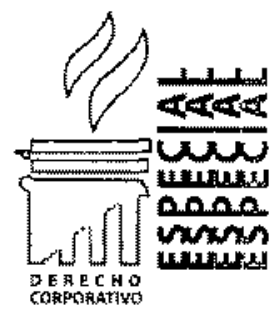


ejerza poder discrecional alguno, sino que actúe en concordancia con las instrucciones o direcciones de un tercero."45 (El paréntesis es nuestrol

Si tomamos esta cita de manera literal, entonces tenemos que el estándar para la determinación de si estamos o no ante un director encubierto. es aquel en el cual debemos esperar que los directores de la sociedad estén exentos de todo poder discrecional, en tal sentido, consideramos que un criterio asi de extremo no puede llevamos a solución satisfactoria alguna, consecuentemente, consideramos que los requisitos para la constitución de la figura del director encubierto se ven aun satisfechos si el directorio de la sociedad controlada mantiene algo del manejo de las políticas sociales.

Señalar por tanto que el directorio no puede ejercer discreción alguna es un requisito innecesario, asimismo que hubiesen desacuerdos eventuales entre las partes en el directorio no evitaría que apareciese la figura del director encubierto. ${ }^{46}$

Por ultimo, la posición que ostentamos es compartida a su vez por el Juez Finn quien en el fallo de Australian Securities Commission vs. AS Nominees señaló:

"La parte de la Sección 60 del Companies Law (de Australia) en la que se hace referencia a aquella persona en concordancia con cuyas direcciones o instrucciones los directores de la sociedad están a costumbrados a actuar, en mi opinión no requiere que tales direcciones o instrucciones involucren todos los asuntos discutidos por el directorio. Más bien, únicamente requiere que, cuando las direcciones o instrucciones sean dadas por el tercero, el directorio esté acostumbrado a actuar (que evidentemente noes lo mismol ".". (Los parén.tesis son nuestros)

Para zanjar tal contraste, consideramos, que donde no existan direcciones o instrucciones formales por parte del director encubierto, por lo menos debe haber algún intento discernible de poder controlar o de influenciar al directorio.

Sustentamos esto, en que el Juez Millet senaló en Re Hydrodam (Corby) Ltd. que un director encubierto "debe tener la intención conciente de controlar las decisiones del directorio. 48 Por otro lado continuó señalando que una persona no debe ser señalada como director encubierto simplemente porque "el directorio, por razones que solo ellos conocen, actuan usando su ibre al bedrio y reflejan potenciales intereses de un accionista mayoritario o influyente, sin haber recibido instrucciones de este o de su representante".t99

De otro lado, el tema del control tambièn fue tocado por el Juez. Hodgson en el caso Standard Chartered Bank of Australia Ltd. vs. Antico en el cual señaló lo siguiente, pese a que existia limitada evidencia de direcciones o instrucciones al directorio de Giant Resources Ltd:

\begin{abstract}
"Desde mi punto de vista, las condiciones impuestas por Pioneer international Ltd. parapro veer de fondos a Giant Resources Ltd en marzo de 1989, demuestran una predisposición y habilidad para ejercer control lejerciendolo efectivamente), sobre la administración generaly en especial financiera de la sociedad".50
\end{abstract}

Las distintas normas analizadas no individualizan a quien se le deben proporcionar estas

45 Jurisdiction de inglaterra: [1995] 18 A.C.S.R. 1. en 637.

46 Jurisdicción de Australia: 1995113 A.C.L.C. 1822 en 1837, Australian Securities Commission vs. AS Nominees.

47 Op. Cit., en 1838 .

48 MLLET, (Judge) Kan, Shadow direcrorship, a real or imagined threat to banks. En: Insolvency Practitioner No. 14, Londies, 1991, p. 16.

49 KOH, Pearlie, Op. Cit., p. 340 .

50 Jurisdiccion de Austalia: [1995] 18 A.C.S.R. I. 
instrucciones. Aunque no está expresamente establecido, interpretes querrán entender que las direcciones o instrucciones sean dadas al directorio.

El argumento contenido en el pàrrafo anterior pudo haber sido acogido por el Juez Thomas en el fallo de Dairy Containers Ltd. vs. NZDIBank Ltd. en vista que señaló que "aún cuando un instrucción clara fue dada por New Zeland Dairy Board, esta fue hecha a Dairy Containers Ltd. y no hacia sus directores, los cuales son personas diferentes.".51

Consideramos en tal sentido, que esa no es la posición adecuada en lo que respecta a este punto.

Requerir en tal sentido que el supuesto director encubierto de las instrucciones directamente al directorio, en circunstancias donde, dependiendo de la jurisdiccion, todos los demás elementos de la regulación han sido cumplidos es exigir lo que la ley no pide.

Consideramos que es suficiente que los directores de la sociedad estèn "acostumbrados a actuar" en concordancia con las direcciones o instrucciones entregadas para que, sin perjuicio de quien o como les fueron comunicadas para que se constituya la figura del director encubierto, asi, ademàs, Markovic es de la opinión que:

"Desde mi punto de vista, si una persona le comunica direcciones o instrucciones a un director (no importando la condición de este ütimo) yeldirectorio estó acostumbrado a actuar, no importando cómo hayan sido entregadas estas instrucciones, ni cuántos intermediarios hayan tenido, entonces la persona que originó tales instrucciones está teniendo una opinion vital, para la conduccion de los asuntos de la sociedad. En tal sentido, existe mérito entonces para argumentar que la persona que comunico tales instrucciones se encuentra sujeta a la regulación de director encubierto y por ende a algunas de las responsabilidades de undirector de la sociedad"t5z

Sin embargo, en tanto lo único que hace es establecer que con una minoria de directores no se podria constituir la figura del director encubierto, al señalar que se requeriria la totalidad de los directores de la sociedad para encontrarnos ante tal figura, consideramos que no es acertado aseverar tal cosa. Sobre este tema nos explayaremos mas adelante.

Por otro lado, la proposición "miembros del directorio" se refiere a todos los integrantes de tal directorio social parece ser que es respaldada por el Juez inglés Millet, quien en Re Hydrodam (Corby) Ltd. señaló:

"La definición, por tanto, no cubre el supuesto en el que una persona se encuentra dispuesta a hacer lo que otra le señale al interior del direc. torio de un sociedad lun pariente, un socio de negocios o alguna otra sociedad que escogió al director en cuestion).

Los alcances de tal definición se encuentran establecidos para los supuestos en los que todo el directorio ha abandonado su responsabilidad en el proceso de toma de sus "propias" decisiones y en cambio se ha acostumbrado a seguir las direc." ciones o instrucciones de un tercero.".33

Es importante por otro lado resaltar que de los fallos estudiados de jurisdicción australiana no se ha podido conseguir una definición sobre cuántos miembros del directorio se requieren para que exista la figura del director encubierto.

Los autores en la materia, como Markovic, sostienen que se lograria poco si se requiriera

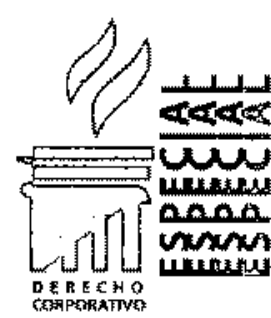


que todos los directores de una sociedad estèn acostumbrados a actuar en concordancia con las direcciones o instrucciones de un tercero no es el sentido de la norma y estamos de acuerdo con eso, pues el gobierno de las sociedades es un gobieno de mayorias.

Como señaláramos lineas arriba, consideramos que para este punto y dependiendo de la jurisdicción, lo razonable para que se dè la figura del director encubierto es que conforme a las direcciones o instrucciones del tercero intere. sado, actuen el numero necesario de directores de la sociedad para implementar una decision o politica de tal sociedad.

Lo anterior responde a que no suena muy lógico permitir que la persona escape a la regulacion de director encubierto simplemente porque la minoría de un directorio no está acostumbrada a actuar en concordancia con las direcciones o instrucciones de este tercero interesado, cuando la mayoría de ese mismo directorio esta decidiendo las politicas sociales y el mismo perjuicio para la sociedad o beneficio para el tercero se puede lograr sin la participación la minoria excluida.

\section{EL NEXO CAUSAL EN EL MARCO DE LA FIGURA DEL DIRECTDR ENCUBIERTO}

En concordancia con los principios generales, debe existir un nexo causal entre el hecho y el daño causado a efectos que se pueda imputar una responsabilidad.

El hecho causa un daño y tales daños pueden producirse en cascada; pues, como consecuencia del dan̆o directo puede sobrevenir un daño indirecto.
En el caso de la responsabilidad de los directores de una sociedad, los supuestos bajo los cuales un director puede causarle un dano a la sociedad, a los accionistas a a terceros interesados se encuentra tipificado por la propia normativa.

Con relacion a los directores encubiertos, la normativa de los paises que recogen tal figura, lo que realiza es una extensión de la responsabilidad de los directores de la sociedad para que esta incluya a los directores encubiertos en los supuestos especificados claramente por la propia normativa, con lo que los remedios a ser aplicados a los directores de la sociedad le serán extendidos a los directores encubiertos de esta bajo los mismos supuestos y regulacion.

Asi nos lo confirma Pearlie Koh, la cual no señala que:

"En la mayoría de jurisdicciones, la legislacion sobre sociedades extiende la definicion de director ofin de incluir a los directores encubiertos. Es consecuencia de esta extension legislativa, que la responsabilidad impuesta a los directores sera de aplicación a los directores encubiertos de ser el caso".54

A modo de ejemplo, si el director de una sociedad con pleno conocimiento del manejo

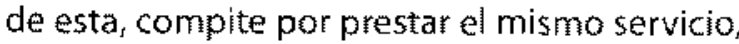
evidentemente haciendo uso de los conoci. mientos adquiridos en el marco de sus funciones como director de la sociedad, entonces la sociedad con la que compite verá disminuidas sus ventas, y como consecuencia disminuiran las utilidades (de ser el caso) con la posible consecuencia de no poder repartir dividendos entre sus accionistas. Ello, a su vez, puede causarle un daño no solo a la sociedad, sino tambièn a los

54 Correo electrónico enviado por Pearle Koh al autor de este tabajo con fecha 12 de julio de 2007 : Martin:

In most common law jurisdictions, the companies' legislation extends the definition of 'director' to include the shadow director. By reason of this legislative extension, the responsibilities imposed by the legislation would apply. where velevant, to the shadow director.

Hope this helps.

Good luck.

Pearlie Kon 
accionistas que dependían de dicho dividendo para honrar sus respectivas obligaciones. En el supuesto que el hecho de competir con la sociedad se encuentre prohibido también para los directores encubiertos de esta, entonces la extensión normativa hará que el nexo causal también pueda ser aplicado a los directores encubiertos.

\section{LA EXCEPCIÓN POR ASESORAMIENTO DE ACUERDO CON LA CAPACIDAD PROFE- SIONAL O LA RELACION DE NEGOCIOS}

La figura del director encubierto evidentemente puede causar preocupación a los asesores de sociedades como financistas, contadores, abogados y a los mismos acreedores de las sociedades, entre otras personas que pueden influenciar las decisio" nes de los directores de una sociedad.

Sin embargo en reconocimiento a la naturaleza válida de este tipo de relaciones de asesoría y acreencia (la de asesor-asesorado, la de acreedor-deudor, entre otras), es que en las regulaciones estudiadas, que contemplan la figura del director encubierto, se contempla tambièn una excepcion a esta figura (Caso de Australia Sección 60(2)) la cual prevé en que situaciones una persona no podrà ser señalada como director encubierto de una sociedad.

Esta situación es aquella en la cual los directores de la sociedad "actúan de acuerdo con el consejo dado por una persona que actúä de con" formidad con los conocimientos o habilidades derivados de su capacidad profesional o de la relación de negocios legítima con los directores de una sociedad o con el directorio de esta. ${ }^{25}$

\section{Consejo}

De las definiciones arriba reseñadas y de los casos que estudiaremos mas adelante se pue- de apreciar que la definición dada a la palabra "consejo" afecta severamente la habilidad de los asesores corporativos de mantenerse al margen de la responsabilidad de un director encubierto.

Solo por citar un ejemplo, en Australia, en el fallo de Australian Securities Commission vs. AS Nominees Ltd. se cita que los demandados señalaron que "reconocen que el señor Windsor tuvo infiuencia sobre las decisiones tomadas por el directorio ${ }^{* .56}$

Sostuvo en contra el demandante que "esto se debia aque el señor Windsoractuaba comogerente de las sociedades; introdujo en estas el negocio fiduciario; y estaba envuelto en los negocios de tales sociedades.

Es por esta razón que los directores de la sociedad actuaron en concordancia con 5 us instrucciones".57

Señalaron refutando los demandados que "el consejo prestado por el señor Windsor de conformidad con los conocimientos y habilidades derivados de su capacidad profesional o de la relación de negocios legitima con los directores de una sociedad ocon el directorio de esta".58 (con el objeto de caer dentro de la excepción)

Con el objeto de refutar tal alegato, el Juez Finn señaló lo siguiente:

"Cuando uno analiza las operaciones realiza. das, no puede decirse apropiadamenteque nos encontramos ante directores actuandoen vista del consejo dado por el gerente de conformidad con los conocimientos o habilidades derivados de su capacidad profesional, en concordancia conla Sección 60(2). Lo que sí se puede admitir es que el directorio actuó por lo menos en un número de situaciones de acuerdo con los

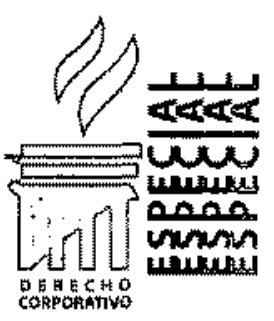


designios del señor Windsor, requiriendo este de aquellos el abandono de sus deberes fiduciarios para con la sociedad".59

Por otro lado, como hemos señalado, debemos entender que la definición de "consejo" difiere sustancialmente de la de "direcciones o instruccion" ${ }^{\prime 60}$ "Direcciones o instrucciones" implica necesariamente un elemento de compulsión, de nulo margen de maniobra para los directores de la sociedad.

En contraste la palabra "consejo" se define coma "Consejo. (Dellat. consilum). 1. m. Parecer o dictamen que se da o toma para hacer o no hacer algo". Consecuentemente un "consejo" a diferencia de "direcciones o instrucciones" puede ser rechazado, que es precisamente en lo que consiste la asesoria.

Si podemos aceptar la dicotomia expresada en los parrafos anteriores, la regulación sobre cuándo se considera que existe un consejo o existe un vinculo válido con los directores de la sociedad con motivo de la realización del objeto social de una sociedad no es una excepción en si misma. Solo afirma una cosa, una persona no puede ser calificada como director encubierto de una sociedad, por el mero hecho de ofrecer su"consejo"o "asesoria".

Por tanto será tarea del juez competente determinar si un asesor ha estado brindando "consejo"o "asesoría"o impartiendo "direcciones o instrucciones" según los hechos de cada caso en concreto. ${ }^{61}$

Sin embargo, se entiende que un asesor, no podria ser señalado como director encubierto solo porque una sociedad sigue su "consejo" o "asesoria", el cuales consecuencia de una necesidad comercial o económica.

En esas circunstancias, se debe poder reconocer que el proceso de toma de decisiones permanece en poder del directorio. Debe recordarse que el asesor es una persona contratada por la empresa para brindar sus servicios profesionales, para un proyecto o tema en particular o para que estos sean brindados periodicamente o cada vez que se requieran, pero es decisión del directorio adoptar o no las medidas que èste recomiende, recayendo por lo tanto sobre los miembros del directorio la responsabilidad que acarree la adopción de la decisión.

Coincidimos en que existen tambièn circunstancias excepcionales que conllevan a que el asesor cobre poder dentro de la empresa siendo el tipico caso, el del asesor que por el transcurso de los años es considerado una figura de poder, opinando que en tal caso igualmente la responsabilidad por la adopción de los acuerdos es del directorio, el que es responsable por la dirección y administración de la empresa y, por lo tanto, se encuentra obligado a detener $y / 0$ impedir la conducta de cualquier persona que atente contra los intereses de la misma, aun cuando la asesoria brindada por el asesor que cobró poder pueda ser confundida con direcciones o instrucciones impartidas por este.

\section{De conformidad con los conocimientos o habilidades derivados de la capacidad profesional}

En adición con que los asesores deben procurar evitar cualquier tipo de mensaje que pueda

59 Jurisdiccion de Australia: [1995] 13 A.C.L.C 1822 en 1838.

60 En lo que respecta a la legistación austaliana por ejemplo, Michael Markovic crea una construccion tecrica para argumentar que "consejo" y "direcciones o instrucciones" no son un concepto distinto. Por otro lado se argumenta que si se hubiese buscado un significado similar se hubiese usado el mismo lenguaje cosa que no ha sucedido. $5 \mathrm{e}$ sugiere además que si "consejo" $y$ "direcciones e instrucciones" fuerar sinonimos, el amplio espectro de los termi" nos "capacidad profesional" y "relación de regocios" crearia una excepción tan amplia que virtualmente cualquier persona que se dedicara a los negocios, podria caber dentro de ella, con lo que el ratio reat de la excepcion se des. virtuaria.

61 BAXT, Rudolph, Liability of shadow director for insolvent trading - Australian authorities start to bite. En: Company and securities law journal. No. 121. Wellington, 1996, p. 142. 
asemejarse a una "dirección o instrucción". La excepción (sin perjuicio que explicamos que ya no es tal) contemplada en las regulaciones estudiadas, implica que el asesor solo debe aconsejar a la sociedad de conformidad con las conocimientos o habilidades derivados de 54 capacidad profesional o de la relación de nego" cios legítima con los directores de una sociedad o con el directorio de esta.

En este supuesto quisimos hacer nuestra la definición usada en Australia en tanto es más amplia que la de Inglaterra, dado que esta solo hace referencia a "consejo dado dentro de las conocimientos o habilidades derivados de su capacidad profesional."

La parca definición usada en Inglaterra ha causado gran preocupación en el sector financiero del pais, en tanto preliminarmente los jueces ingleses han considerado que los bancos no dan consejo de acuerdo con los"conocimientos derivados de su capacidad profesional" sino màs bien derivados de los intereses que pueden tener estos agentes en una sociedad y asílo de* muestra el caso Re MCBacon Ltd. que hasta que fue abandonado se llevo ante el Juez Millet. ${ }^{62}$

El análisis relevante radica en saber si un asesor seria responsable por brindar consejos más allà de los alcances de su capacidad profesional o de una relación legitima de negocios (queremos ser enfáticos en señalar que "la relación legitima de negocios" proviene de la normativa australiana y no existe en la inglesa):

Al ser un tema subjetivo, ¿què podria considerar un juez que sería asesoramiento en ejercicio adecuado de los conocimientos o habilidades derivados de la capacídad profesional del agente o la relación legítima de negocios con los directores de la sociedad?

Solo por citar un ejemplo, ¿puede un abogado (encargado de brindar asesoramiento legal) asesorar a una sociedad en temas financieros y comerciales?

Consideramos en este punto que la asesoría de un abogado en materias financieras haria incurrir a este en responsabilidad profesional por brindar asesoría negligente (salvo que tuviese experiencia relevante en la materia, la cual de. mostrará), pero nos preguntamos a su vez isería este asesoria o consejo negligente, suficiente para convertir a este asesor en director encum bierto de una sociedad? Creemos que no.

Si bien es prudente que los asesores en una materia (sea cual fuera) se limiten a asesorar solo en ella, desde nuestro punto de vista, ofrecer consejo en materias mas allá de su capacidad profesional no sería suficiente para acarrear responsabilidad a tal asesor bajo la figura del director encubierto.

Que los directores de una sociedad siguieran consejos de un asesor más allà de la capacidad profesional de este podria implicar para ellos, en caso el consejo seguido hubiese acarreado consecuencias negativas para la sociedad, una demanda de responsabilidad para los directores por negligencia pero no hubiese configurado, como seńalamos en el párrafo anterior, la figura del director encubierto. ${ }^{63}$

Asimismo, como ya hemos apuntado, un elemento esencial de la figura del director encu-

62 Es importante notar que a diferencia del resto de jurisdicciones en las cuales analizamos la figura de los directores encubiertos, en jurisdicciòn de Austalalia la excepciòn es màs amplia contemplando el tèrmino "relación de nego" ciost. Al respecto de esto Michael Markovic señala que ofiginalmente en Australia la provisión sobre directores encubieftos en cuanto a la excepción solo hacia referencia a las personas que ofrecian consejo dentro de sus competencias profesionales. Con posterioridad a la entrada en vigencia del Companies Code de Australia la inclusión del término "relación de negocios" se hizo. Finalmente el Memorando Explicatorio de la modificación, reitera Michae! Makovic, es de poca ayuda para establecer la motivación de los legistadores para extender la aplicacion de la excepción.

63 GIRVIN, Stephen, Statutory liability of shadow directors. En: Juridical review, No. 414, Sweet \& Maxwell, London, 1995 , p. 212 .

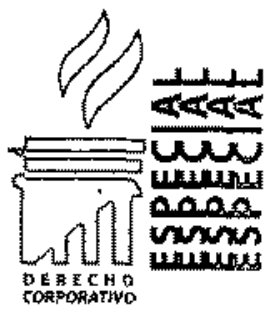


bierto es comunicarles a los directores de la sociedad, "direcciones o instrucciones".

De lo estudiado, entendemos que el soporte para la búsqueda y aplicación de la figura del director encubierto no radica en que la persona brindó consejo o asesoria de conformidad con los conocimientos o habilidades derivados de su capacidad profesional o de la relación de negocios legítima con los directores de una sociedad o con el directorio de esta. ${ }^{64}$ sino que el fundamento radica en si la persona ofreció solamente "consejo o asesoría o comunicó "direcciones o instrucciones" al directorio.

Consideramos que las palabras "direccio" nes o instrucciones" no abarcan a la palabra "consejo".65 Consecuentemente, si aceptamos esto, entonces el espectro de la frase "de conformidad con los conocimientos o habilidades derivados de su capacidad profesional o de la relacion de negocios legitima con los directores de una sociedad o con el directorio de esta" aumentaria en importancia.

Sin embargo, un amplio grupo de personas podrian encontrarse comprendidos por una relación de asesoria o de negocios haciendo de los alcances de esta excepción demasiado amplia tanto que la regulación y alcances de la figura del director encubierto podria verse mermada y este no puede ser la intención en una regulacion de estas caracteristicas.

Como observa Michael Markovic, "existe aun un alto grado de incertidumbre alrededor del campo de acción de este tipo de excepciones.66

Sin embargo y existiendo una regulación de excepción como esta, todo tipo de asesores en una sociedad que puedan influir en las decisiones de esta deberán ejercer tal asesoría con precaucion.

64 Jurisdiccion de Australia: [1995] 13 A.C.L.C. 1822 en $\$ 838$.

65 Jufisdiccion de inglatera: [1994] 2 B.C.L.C. 180 en 330.

66 Juristicción de inglaterra: [1994]2 B.C.L.C. 180 en 335 .
Ahora bien, las cortes en las distintas jurisdicciones donde se aplica la figura del director encubierto se han mostrado flexibles desde nuestro punto de vista, al momento de analizar la asesoria y las relaciones de negocios de terceros con los directores de una sociedad o el directorio en su totalidad.

Por citar un ejemplo, en el fallo del Juez Knox en Re a Company (No. 005009 of 1987) ex parte Copp. causaron preocupacion en sectores financieros, dado que el juez expresó que en este caso en particular el banco no era ni habia adquirido en momento alguno la condición de director encubier to de la sociedad, pero que, $\sin$ perjuicio de eso consideraba posible tal cosa, según Michael Markovic, fallos recientes en la materia han sido reacios a declarar a bancos y otras entidades financieras responsables como director encubierto de sociedades.

Es importante puntualizar que consideramos que los bancos no deberian ser señalados como directores encubiertos pues no vigilan el crecimiento económico de las sociedades -aún cuando dicha vigilancia les podria ser conveniente, pues aseguraria la cobranza de sus créditos-pues ese no es su negocio, el cual se basa en obtener ganancias por el cobro de un interes sobre el capital prestado, entre otros. El banco no obtiene mayores ganancias si la sociedad es más rentable, ni le permite a esta pagar menos si atraviesa por un mal momento económico. Es más, el banco se encuentra obligado a provisionar los créditos de las sociedades que considere en riesgo de pago. Consecuentemente, si el banco de alguna forma dirigiera los intereses de la sociedad, ello conllevaría que: (i) se abocaría a lograr un crecimiento económico de la misma; (ii) la normativa le permitiria lograr mayores ganancias como consecuencia de una diligente supervisión; y (iii) no le otorgaria créditos a sociedades que no se encuentren por él dirigidas, conlo que no se veria jamás obligado 
a provisionar o castigar crèdito alguno, pues se encargaria de la buena marcha de tal sociedad, con el fin de recuperar su crédito y para obtener, como se ha dicho, mayores ganancias. Igualmente, los bancos no tienen razón alguna para perjudicar los intereses de las sociedades, desde que les conviene que estas se conduzcan exitosamente, pues ello le asegura la recuperación de su crédito y reduce el monto de las contingencias que puedan manejar.

\section{Claro es el caso en Re PFTZMLId. Jourdain y Otros} vs. Pau $\left.\right|^{67}$ de jurisdicción inglesa donde en su fallo el luez Baker señaló que, "sin perjuicio que funcionarios del banco habían participado de directorios semanales en la sociedad durante un periodo de dos años, el banco no era un director encubierto de la sociedad, dado que estos funcionarios del banco actuaban, no como directores de la sociedad, sino en defensa de los intereses comerciales y financieros del banco".

Por otro lado, en un articulo escrito por el Juez Millet con relación al caso Re MC Bacon Ltd. (proceso que fuera abandonado en su oportunidad), este opinó que "mientras que un banco no interfiera en el manejo de una sociedad que es su cliente, esta facultado para imponerle condiciones con el abjeto de mantener las líneas de crédito para tal sociedad".6"

Consideramos que si bien es cierto que las necesidades comerciales de una sociedad pueden conminarla a tomar las condiciones impuestas por el banco (por abusivas que estas puedan ser) creemos también que, la decisión final debe ser del directorio de la sociedad y no del banco que presta el financiamiento necesario, con el objeto que este último no se convierta en director encubierto de la sociedad.

Debe recordarse que la institución financiera lo que busca es asegurar su crédito y la cobranza del mismo, para lo cual estudia y califica a la empresa y requiere o solicita las garantías que considera necesarias para tal fin. El banco no busca incrementar las ganancias de la empresa solicitante ni perjudicarla, no considerando tales circunstancias dentro de su análisis. Por su parte, la empresa, mediante su directorio, puede decidir asegurar el crédito o no; acudir a otro banco, proponer otras garantías o procuràrselas, siendo, consecuentemente responsable por las medidas adoptadas.

Asimismo, el antes mencionado Juez Millet se. ñala algunas de las acciones permitidas por los bancos para que dentro de una relación legitima de negocios no se vean incursos dentro de la figura del director encubierto, a saber:

a) Auditar la sociedad o investigarla.

b) Demandar la reducción del sobregiro.

c) Demandar garantias a priorio a posteriori de un crédito.

d) Solicitar información, como balances, estados financieros y flujos.

e) Solicitar que cualquier propuesta de cambio en las políticas 5ociales, sea acompaña da de los documentos sustentatorios.

f) Aconsejar sobre la deseabilidad de un gerenciamiento más estricto o de la búsqueda de nuevo capital fresco de trabajo (sin buscar que la sociedad haga uso de de lo que en el argot bancario se conoce como "carrusel"),

Tales propuestas hechas por el Juez Millet en el artículo, fueron tomadas por el Juez Hodgson para el caso de Standard Chartered Bank of Australia Ltd. vs. Antico, seña lando:

"Puedo aceptar que no es poco común para aquellas personas que prestan dinero, imponen condiciones a estos prestamos, sobre el destino de los fondos, asi como obligaciones

67 Jurisdicción de inglaterra: [1995] B.C.C. 280; 2 B.C.L.C. 354.

$68 \mathrm{KOH}$, Pearle, Op. Cit., p. 341. Gitando al Juez Millet. 
de informacion con las que debe cumplir el prestatario; es más común aun para aquellas personas que prestan dinero solicitar ga rantías sobre su acreencia (indistintamente de la naturaleza de las mismas), para luego posteriormente exigir la venta de tal garantia para satisfacer su crédito. Ciertamente estos factores por si solos no haria a un prestamista asumir la condición de director encubierto de una sociedad o la gerencia de esta" ${ }^{* 99}$

Habiendo reseñado las definiciones de distintas jurisdicciones sobre lo que implica ser un director encubierto, explicado su naturaleza juridica, el nexo causal de tal figura y entendido los alcances de la excepción impuesta a la misma, corresponde pasar a analizar jurisprudencia representativa en la materia, lo anterior, a efectos de poder ver realmente las implicancias de todo lo revisado con anterioridad.

\section{JURISPRUDENCIA DEL CDMMDN LAW - ULTRAFRAME (UK) LTD, VS. FIELDING AND DTHERS ${ }^{70}$}

En tanto que el origen de la figura del director encubierto surge en Inglaterra y teniendo en consideración el mayor desarrollo en la materia en dicha jurisdiccion. Asimismo, vista la falta de espacio en un trabajo de esta naturaleza, analizaremos un caso que, por su naturaleza, es el más representativo, lo anterior, teniendo en consideración que se ha convertido en el caso líder (leading case) en muchas materias societarias de los últimos años, sobre todo en Inglaterra. En este se discuten desde temas de garantias de la sociedad, incumplimiento de deberes fiduciarios, traspasos de "know how" pasando por, además, dar los lineamientos para el manejo de sociedades que ha revolucionado el tema en inglaterra, sin dejar de mencionar la definición clara y precisa de que es un director de facto y que es un director encubierto llos que analizaremos al final de la reseña). ${ }^{71}$ Este caso es Uitraframe (UK) Ltd. vs. Fielding and others.

Entrando al caso, es importante mencionar que la primera instancia la llevó adelante el Juez de insolvencia y quiebras Jacob, pero se resolvió finalmente el 27 de julio del 2005 , en la Corte de Apelaciones ${ }^{72}$ (segunda instancia), sin periuicio que los mejores alcances del mismo las hizo el Juez Jacobs, siendo la corte la que tomó sus impresiones al respecto.

El proceso tomó 95 días efectivos de audiencias en la corte solo para resolver el tema de las responsabilidades derivadas de los incumplin mientos a los deberes fiduciarios de conducta de los directores y se llevó a cabo realmente, como actores principales, entre Uitraframe (UK) Ltd. y The Burnden Group Plc.

Ultraframe (UK) Ltd. y The Burnden Group P/C. competían en el mercado de "conservadores" para techos de inmuebles.

El señor Gary Fielding y la señora Sally Fielding, su esposa, eran los accionistas mayoritarios de The Burnden Group Plc. (en adelante, indistinta" mente, Gary Fielding o The Burnden Group PIC.).

El proceso tuvo cobertura de los medios debido a la virtual "guerra" que se desató en la corte donde corrian acusaciones y contra acusaciones de falsificacion de documentos, robo, contabilidad paralela, chantaje e incendio premeditado sin mencionar las alegaciones esparcidas de que todos los testigos mentian en el tribunal (perjurio), acusaciones por demás serias.

69 Kort, Pearile, Op. Cit.. p. 341.

70 Lurisdicción de Inglatera: [2005] EWCH 1638 [Ch].

Se acumularon los siguientes procesos: HCO3C03199. HCO3C03545, HCO3C0992 y el HCO2CO2548.

71 Es curioso senalar, que los demendados no fueron encontrados difectores encubiertos sino dirctores de facto, de la sociedad, pero para llegar a esta conclusión el Juez Lewison tuez ponente del caso en la Corte 5 uperior) estableció lineamientos profundos de estudio sobre la figura de los directores encubiertos y de los directores de facto.

72 High Court of usstice Chancery Division. 
El trasfondo real del proceso era una disputa por la propiedad de negocios que se hacian competencia mutuamente o en su defecto el retiro de uno de estos del mercado.

Uitraframe (UK) Ltd. era de propiedad del señor Howard Davies. Este último operaba a través de una serie de sociedades las cuales devinieron todas en insolventes. En el proceso de ruina Howard Davies adquirio dos sociedades, Northstar System L Ltd. y Seaquest Systems Lid, estas con el tiempo también devinieron en insolventes y fueron efectivamente controladas por Ultraframe (UK)Ltd.

Sin perjuicio que la demanda en contra de Gary Fielding y Sally Fielding fue llevada a cabo por el liquidador de Northstar Systems Ltd. y Seaquest System $L$ Ltd., del expediente se desprende que no queda duda que tal acción de responsabilidad fue azuzada por Howard Davies a travès de Utraframe (UK) Ltd., de ahi el nombre del caso.

Ultraframe (UK) Ltd. demandó que Gary Fielding y sus allegados habian robado el negocio y los activos de Northstar Systems Ltd. y Seaquest Sys. tems $L$ td., la demanda es consecuencia de:

- La deshonesta información proporcionada a Howard Davies por parte de Gary Fielding y sus allegados incluyendo entre ellos a los señores Birkett, Naden y Clayton con la intención de venderle las sociedades denominadas Northstor Systems Ltd. y Seaquest Systems Ltd. que segùn los señores Naden y Clayton alegaban, les pertenecían a ellos, pero cuyo real beneficiario y propietario era Gary Fielding. Sociedades cuyos activos habian sido ade más comprometidos previa mente, para la satisfacción de los créditos de los acreedores de Gary Fieiding.

- La contestación hecha por Gary Fielding y sus allegados a la demanda planteada por Uitraframe (UK) Ltd. es que, en efecto, Gary
Fielding era propietario interpositapersonae de las acciones de Northstar Systems Ltd. y de Seäquest. Systems Ltd. y que a la vez era un acreedor garantizado de ambas, en tanto les suministró fondos, lo que prevenia que UItraframe (UK) Ltd. dispusiera de los activos sin pagar las deudas previamente, cosa que no es ilegal..$^{33}$

The Burnden Group Plc. señalò en parte durante el proceso que U/traframe (UK) Ltd. habia iniciado una campaña para sacar a sus competidores del mercado, mediante demandas que se sucedian unas a otras, forzando a sus competidores a solicitar la insolvencia, señalando Gary Fielding que aunque $U$ /traframe (UK) Ltd. se ha esforzado en esbozarlo como un conspirador y un ladròn, él es de hecho la victima de esta situación.

Agregando Gary Fielding que a partir de marzo de 1997 se comenzó progresivamente a vincular más con Northstar Systems Ltd. y Seaquest Systems Ltd. debido a una serie de operaciones comerciales con ellas (como contratos y provisiòn de materia prima, contratos de préstamos de proveedores entre otros).

Uitraframe (UK) Ltd. alegó a su vez que tal rem clamo era falso y que los documentos en los que Gary Fielding sustentaba su posicion eran fabricados o burdas falsificaciones y que Gary Fielding era parte de un conciliabulo que bus* caba estafar a U/traframe (UK) $L$ td.

Sin embargo a través de la declaración del señor Birkett en corte (uno de los allegados de Gary Fielding como señalàramos líneas arriba), se obtuvo una perspectiva clara del esquema para defraudar a Uitraframe (UK) Ltd:

"Hacia fines de octubre de 1998, Gary Fielding tuvo un reunion con los señores Birkett, $\mathrm{Na}$ " den y Clayton en "The Nag's Head" un pub en Altricham. Se discutio que, dada la situacion, Howard Davies iba a intentar una toma de

73 Se demostro durante el proceso, que la intencion de Gary Fielding, era quitarle a esas empresas recientemente adquiridas por Howard Davies todos sus activos, usando como medio para ello, otras empresas de las que era pro pietario. 
controlde Northstar Systems Ltd. y de Seaquest Systems Ltd. y que estaban dispuestos a recibir instrucciones de Gary Fielding. Gary Fielding señalo que las acciones en Northstar Systems Ltd. y Seaquest Systems Ltd. tenian que ser transferidas a el y/o que debian encontrar la manera de que todos los activos de ambas sociedades queden asegurados en su favor.

En sintesis el objeto de la reunión era discutir coartadas posibles y plausibles acerca de la forma en la que Gary fielding adquiriria las acciones de Northstar Systems L.t. y Seaquest Systems $L$ td. Ellos sabian que requerian encontrar una justificacion para poder decir que Gary Fielding tenia una relacion de larga data con ambas sociedades lo que justificaria a su vez la toma de garantias de Gary Fielding sobre los activos de las sociedades. Se acordo que se demostraria que Gary Fielding tomo el control de Northstar Systems Ltd. y Seaquest Systems Ltd. antes de junio de 1998 y desde ese punto fue que evoluciono fa histonia".74

Despues de un largo proceso judicial de dos años, la sentencia de los expedientes acumulados fue en resumen la siguiente:

- Gary fielding se convirtió en un director de facto de Northstar Systems Ltd. y Seqquest Systems Ltd. en enero de 1999, nunca en un director encubierto en tanto el directorio de ninguna de las dos actuaba en concordancia con sus instrucciones. Se determinò que el era un director de facto en tanto el mismo señaló que estaba "manejando la sociedad".

- Gary Fielding tenia deberes fiduciarios para con Northstar Systems Ltd. y Seaquest Systems Ltd. dado que se podia apreciar de las cuentas corrientes de las sociedades que él podia disponer de sus fondos.

- Las deudas garantizadas de Northstar 5ystems Ltd. y Seaquest Systems Ltd. a favor de Gary Fielding son declaradas válidas.
Finalmente, sin perjuicio que se declaró a Gary Fielding como director de focto y no como director encubierto pasaremos a reseñar el anátisis hecho por el Juez Jacobs (razonamiento que fuera acogido por la Corte de Apelaciones de Londres), sobre lo que quiere decir cada uno de los terminos, teniendo en consideración que el objeto de esta tesis es solo la figura del director encubierto y que por tanto nos centraremos en ella.

"La Corte de Apelaciones de Londres que confirmaria la sentencia del Juez Jacobs haciendo suyo todos los extremos de la misma, señaló asimismo que en la práctica director encubier to implica:

- Que ante la pregunta ¿Quién debe estar acostumbrado a actuar? La respuesta indubitable sea, la mayoria del directonio con la capacidad suficiente para gobernar a la sociedad debe estar acostumbrada a actuar en concordan. cia con las instrucciones del que se cree es un director encubierto. Continúa señalando que la intencion de la norma es encontrar a la persona que efectivamente controla el devenir de la sociedad al controlar al directorio. En tal sentido una personano puede ser director encubierto de una sociedad si controla la menoría del directorio de esta. (El subrayado es nuestro)

- Que ante la pregunta ¿Cómo deben reaccionar ante la instrucciones proporcionadas? Evidentemente, actuar en conformidad con esas instrucciones. No es suficiente que el supuesto director encubier to haya dado instrucciones o direcciones, sino que estas hayan sido implementadas por el directorio y convertidas en acciones.

Asimismo complementan señalando básicamente que el actuar de este directorio controlado por el director encubierto, implica un actuar regular acatando sus instrucciones, como patrón de conducta, en un espacio de tiempo determinado. ${ }^{75}$

74 Jurisdicclón de inglatera: [2005] EWCH 1638 (Ch) en 1257.

75 Jutisdiccion de Inglatera: [2005] EWCH 1638 (C) on 1258. 
Como se señaló pàrrafos arriba, desde el mo mento en el que se puede establecer que la mayoria del directorio de una sociedad con la capacidad de tomar las decisiones en ella esta acostumbrada a actuar en concordancia con las direcciones o instrucciones del supuesto director encubierto, este tiene ciertos deberes para con la sociedad controlada. No cumplir con ellos implicaria posiblemente consecuen " cias para el director encubierto o la sociedad controlada.

"En el caso Ultraframe (UK) Ltd. vs. Fielding y Otros, la Corte de Apelaciones de Londres se toma por primera vez el trabajo de analizar in extensum los alcances de estos deberes, señalando para los alcances reales de la ley en la materia, lo siguiente:

Los deberes de un director encubierto no se aplican retrospectivamente al momento en el cual la mayoría del directorio comenzó a actuar en concordancia con sus direcciones o instrucciones, si no que se limita al momento en que consecuencia de estas dírecciones o instrucciones los directores incumplieron un deber hacia la sociedad.

El director encubierto que no maneja directamente algún activo de la sociedad no tiene hacia esta ningún deber fiduciario, consecuentemente no tiene el deber de actuar en el mejor interés de la sociedad y el deber de no realizar ganancias desde la posición que ostenta, deber que si tienen los directores de una sociedad.

- Sin embargo ciertos deberes legales si les son aplicables a un director encubierto:

1. Un director encubierto esta obligado a declarar al directorio el interés o conflicto que tiene ante cualquier negociación, contrato preparatorio o contrato que se le presente.
2. Un director encubierto debe declarar su condicion, sus intenciones e intereses frente a cualquier paquete accionario que posea o que desee adquirir asi como ante la emisión de cualquier obligación por parte de la sociedad de la que es director encubierto.

3. Cualquier transaccion en la que lo sociedad adquiera un activo o viceversa, requerira de la aprobación previa de la Junta General de Accionistas de la sociedad, si esta aprobación no se obtiene, la transacciones potencialmente anuloble--como condición se debe tener en cuenta que la transacm cion debe ser por un monto minimo de $\mathrm{E}$ 100,000.00 (Cien mily 00/100 Libras Esterlinas) o igual al 10\% (por ciento) del valor de los activos de la sociedad en libros.",6

Por otro lado en la misma exposición de moti vos, la Corte de Apelaciones de Londres explicó los alcances de lo que implica ser un director de facto, que como señaláramos no es ni será objeto de esta investigaciòn, pero que considew ramos que para efectos pràcticos es importante reseñar, sobre todo de acuerdo con lo que la jurisprudencia nos señala en la materia en tal sentido:

- "Un director de facto es aquella persona que realiza las funciones de un director de acuerdo con el Companies Law de Inglaterra, pero que no ha sido formalmente nombrado como director. La Corte Superior puntualizo en Ultraftame (UK) Ltd. vs. Fielding y Otros que "un director de facto es aquella persona que asume funciones que probablemente solo te competen a un director y que asimismo esta persona tiene la habilidad para lograr particim par del proceso de toma de decisiones em una sociedad"?"

- Es poco probable que una persona sea un director encubiertoy un director de facto a la

76 Jurisdicción de Inglaterra: (20051 EWC: 1638 (Ch) en 1259-1260.

77 Jurisdicción de Inglaterya: [2005] EWCH 1638 (Ch) en 1261. 
vez, sin embargo es posible que una persona ser primero un director encubierto de una sociedad para posteriormente convertirse en director de facto de la misma.

- Es posible que una persona sea ala vez director encubierto de una sociedad y director de facto de otra. ${ }^{78}$

- Ante la pregunta sobre ¿Qué deberes tiene un director de facto de la sociedad hacia ella? $\mathrm{La}$ respuesta es, que un director de facto tiene hacia la sociedad los mismos deberes fiduciarios, legales y estatutarios asi como prohibiciones que un director legalmente nombrado por la sociedad".

Finalmente la misma corte analizó las implicancias para con los directores y accionistas de una sociedad en relación con las figuras del director encubierto y el director de facto, los cuales no consideramos ocioso reseñar brevemente:

- "Los directores de una sociedad deben revisarel proceso de toma de decisiones en el directorio regulamente, as como la de los principales funcionarios de la sociedad, para asegurarse que no están acostumbrados a actuar en concordancia con las instrucciones de personas que no son directores, asi como para asegurar que tales funcionarios no son directores de facto de la sociedad.

- Los accionistas, incluyendo las sociedades matrices, que tiene la posibilidad de nombrar a uno o mas directores en el directorio, deben revisar su forma de trabajo, para asegurar que quienes "representan sus intereses" no se vean infuenciados en exceso en la toma de decisiones en el directorio, para que tales accionistas no caigan dentro de los alcances de la definición de director encubierto."

Finalmente, consideramos que, no existe gran cosa que agregar para aclarar un caso cuya

78 Jurisdiccion de inglatera: [2005] EWCH 1638 (Ch) en 1264.

79 Sección 309. del Componies Act 1985 de Inglatera.

80 Sección 320. del Companies Act 1985 de Inglaterra.

81 Sección 322B. del Companies Act 1985 de Inglatera. explicación e implicancias se desprenden por si mismas.

\section{IMPLICANCIAS DE ENCONTRAR A UN DIRECTOR ENCUBIERTO}

Habiendo analizado, entre otras cosas, la definición, naturaleza juridica, nexo causal, así como la jurisprudencia, compete en este punto hacer una reseña de lo que implica encontramos ante un director encubierto.

De acuerdo con las distintas leyes revisadas provenientes de distintas jurisdicciones, creemos que, en tanto es Inglaterra la matriz de esta figura y que en cuanto a los alcances y responsabilidades, es la que ha desarrollado más el tema a traves del Company Act 1985 , el Insolvency Act 1986 y el Company Directors Disqualification Act 1986, aunado a que en cuanto a las implicancias de ser un director encubierto, el resto de jurisdicciones que regulan tal figura, se ha limitado a copiar la regulación contemplada por Inglaterra, convirtiendo en ociosa su repetición, consideramos importante en este punto, con el objeto de tener un criterio único al respecto, evitando la confusion, señalar solo las implicancias bajo la jurisdicción inglesa, a saber:

- Los directores encubiertos de una sociedad tienen el deber de velar por el mejor interés de los empleados de una sociedad como si fueran directores de jure de esta. ${ }^{79}$

- Provisiones especiales para la negociación de activos y propiedades sustanciales de la sociedad, entre esta y los directores de la sociedad les son aplicables a los directores encubiertos.

- Si la sociedad posee solo un accionista, cualquier acuerdo de esta sociedad con el director encubierto, debe ser hecho por escrito. ${ }^{81}$ 
- Todas las regulaciones aplicables para prés. tamos a empleados, funcionarios y directores serán de aplicación para los directores encubiertos de la sociedad

- Los directores encubiertos deberán declarar su interés (cualquiera sea este) ante una negociación, contrato preparatorio o contrato mediante el cual sea posible o se vaya a vincular la sociedad controlada. ${ }^{83}$

Está prohibido para un director encubierto el negociar con contratos de opción de la sociedad, de acciones, instrumentos de deuda $y$ activos de esta. ${ }^{\text {gh }}$

- El director encubierto tiene la obligación de divulgar la propiedad de acciones de la sociedad de la que es director encubierto, tal y como se le aplica a los directores de la sociedad. ${ }^{85}$

Creemos que merece mención aparte, el hecho que consideramos que para este caso el director encubierto deberá señalar cualquier forma que tenga de ejercicio de los derechos politicos sobre las acciones de la sociedad de la que es director encubierto, pues si bien los derechos económicos de las mismás son importantes, más lo es en este caso, consideramos, la capacidad de decisión sobre los asuntos de la sociedad por lo mismo que estamos en este caso analizando una figura que lo que busca es controlar a una sociedad desde la sombra.

- Un director encubierto puede ser encontrado responsable por Wrongful Trading, lo que permite al liquidador de una sociedad buscar una contribución por parte del director encubierto de sus fondos personales a título de reparación, si la sociedad es liquidada consecuencia de un proceso de insolvencia, y se puede demostrar además, que el director encubierto sabia o pudo saber que la sociedad no podria evadir la liquidacióny aún asi no hizo nada para impedir que esta siguiera operando o contratando ${ }^{\circ 6}$, así como se le aplica tal regulación a los directores de una sociedad en esas circunstancias.

- La Secretary of State and Industry puede imponer al director encubierto una orden de descalificación para el ejercicio del cargo de director de una sociedad por plazos que van desde los dos (2) años, hasta los quince (15) años, dependiendo de la falta cometida. ${ }^{87}$

El objeto de esta revisión sobre las implicancias de la figura del director encubierto en Inglaterra, es señalar los criterios de aplicación a tenerse en cuenta al momento de desarrollar el trabajo normativo para jurisdicciones donde esta figura aún no ha sido regulada, en tal sentido consideramos importante tener en cuenta este punto para un futuro análisis.

Finalmente, es importante señalar que, tener claros los criterios de aplicación de una figura en la jurisdicción donde se creó; genera una ventaja cuantitativa, pues permite comparar y saber qué alcances de esta figura se encuentran ya contempladas o son similares en la constelaw ción normativa donde la figura estudiada quiere ser implementada, haciendo más sencilla su adaptación.

\section{VIII.DEFENSA DE LOS DIRECTORES O DE LOS DIRECTORES ENCUBIERTOS}

Sin perjuicio que nos gustaria explayarnos en la materia, pasaremos a reseñar brevemente, por

82 Secciones $330 \div 346$. del Companies Act 1985 de Inglatera.

83 Sección $317(8)$. del Componies Act 1985 de Inglaterra.

84 Seccion 323. del Companies Act 1985 de Inglaterra.

85 Sección 324. del Companies Act 1985 de inglaterra.

86 Seccion $214(7)$. del insolvency Act 1986 de inglatera.

87 Secciones 6-9 y 22(4), del Companies Directors Disqualification Act 1986 de inglatera. 
no ser objeto de esta tesis, lo que a saber de las cortes inglesas implican las medidas defensivas de los directores (de jure o de facto) y de los directores encubiertos.

Se entienden por medidas defensivas a todos aquellos actos o concatenación de los mismos destinados a minimizar las perdidas potenciales que le podría acarrear a un director o director encubierto de la sociedad, actuar ilicitamente en el ejercicio de su cargo ${ }^{83}$

Concretamente, en el caso de un director encubierto, implicaría por ejemplo hac er constar en las actas de directorio de la sociedad que controla, las instrucciones que comunique a los directores de esta, sean consignadas en su totalidad, con el objeto de dar una apariencia de independencia de los directores de la sociedad controlada. ${ }^{89}$

Esta pràctica (la consignación en acta de la totalidad de la discusión) es poco usual por ejemplo en jurisdicciones como la peruana, donde la Ley General de Sociedad no lo estima obligatorio.

Finalmente, segùn jurisdicción inglesa, aquel director o director encubierto que se encon"' trado responsable de haber incurrido en esta conducta (actitudes defensivas de actuaciones ilicitas) deberá, ademàs de las responsabilidad por la actuación ilicitas de las que sea declarado responsable, hacer el pago de una reparación proveniente de fondos personales hasta ellimite que la corte estime pertinente, no teniendo este pago el titulo de penalidad sino de reparación, así como serà sujeto a un probable descalifícación de la posibilidad de ser director de una sociedad, por un periodo que puede ir desde los dos (02) años, hasta un máximo de (15) quince años de acuerdo con la Disqualification Act 1986 de inglaterra.

\section{IX. ¿QUIEN PUEDE SER SUJETO DE RESPON - SABILIDAD A LA LUZ DE LA FIGURA DEL DIRECTOR ENCUBIERTO?}

De los puntos analizados se desprende que los terceros que deberian estar preocupados de calzar dentro de los alcances de la figura del director encubierto, son los asesores profesionales, expertos en negocios, sociedades matrices, accionistas controladores y cualquier tercero con interés en manejar los asuntos de la sociedad, por ejemplo, directores de inversionistas institucionales.

Por otro lado, podemos entender, del fallo para el caso Re Hydrodam (Corby) Ltd. Que bancos y financistas no necesitan preocuparse demasiado, por ser encontrados como directores encubiertos de una sociedad, sin embargo esta posición es en todo caso argumentable.

Sin embargo la posición del asesor es menos sólida que la de los bancos y financistas. ${ }^{92}$

88 CAMPBELL, Nicholas R., Op. Cit., p. 138.

89 GIRVIN, Stephen, Op. Cit., p. 215.

90 "Articulo 170.-Actas

Las deliberociones y acuerdos dei directorio deben ser consignados, por cualquier medio, en actas que se recogeran en un libro, en hojas stieltas o en otra forma que permita la ley y, excepcionalmente, conforme al Articulo 136.

Las acias deben expresar. si hubiera habido sesion: la facha, hora y lugar de celebracion y el nombre de los concurrentes; de no haber habido sesion: la forma y circunstancias en que se adoptaron el o los acuerdos; y en todo caso tos asumtos tratados. Jas resoluciones adoptadas y el numero de votos emitidos asi como las constancias que quieran dejar tos directores. (...)" (E) subrayado es nuestro).

RAFFO, Carlos, La administracion de las sociedades anonimas. Aspectos juridicos de un debate judicial, Didi de Arteta S.A., Lima, 1995, p. 211.

91 KOH, Pearlie, Op. Cit., p. 341.

92. Aun $\sin$ perjuicio de las protecciones dadas en cada jarisdiccion para tales asesores por bindar consejo de acuerdo con sus habilidades profesionales. Pues la linea divisoria entre un director encubierto y un asesor puede ser dificil de trazar. 


\section{LA FIGURA DEL DIRECTOR ENCUBIERTO SEGÚN LA COMPANIES ACT 2006}

Sin perjuicio que se ha explicado y trabajado la figura del director encubierto, consideramos que la evolución de la figura deberá ser tratada enesta parte, en tanto la misma trata sobre la nueva Companies Act 2006 y las diferencias que existen con la norma en actual vigencia. Consecuentemente, se hace necesario reseñar la figura del director encubierto bajo la normativa inglesa que, para los efectos de esta sección en particular entrará en vigencia en enero del año 2009.

En ese orden de ideas, la Companies Act 2006 de Inglaterra en su Sección 251 señala:

\section{1 "Director Encubierto"}

(1) En la Companies Act "director encubierto", con relacion a una sociedad, quiere decir una persona en concordancia con cuyas direcciones o instrucciones los directores de una sociedad están acostumbrados a actuar.

(2) Una persona no deberá ser señalado como director encubierto por la única razón que los directores actuen de acuerdo con los consejos otorgados por este de acuerdo con su capacidad profesional.

(3) Una sociedad no podrá ser señalada como director encubierto de ninguna de sus subsidiarias para los propósitos de:

Capitulo 2 (deberes generales de los directores)

Capítulo 4 (transacciones que requieren la aprobación del directorio)
Capítulo 6 icontratos con una persona que a la vez es director de la sociedad), por la única razón que los directores de la subsidiaria estèn acostumbrados a actuar en concordancia con sus direcciones e instrucciones.

Asi, a diferencia de la definición de director encubierto contenida en la Sección 741. de la Companies Act 1985, donde la definción de director encubierto se encuentra contenida en la misma sección que define al director, la Companies Act 2006 contempla para la figura del director encubierto una sección propia, lo que consideramos el cambio más resaltante respecto de la legislación sobre directores encubiertos, pues al mantener ahora una sección propia, que no depende de las diferencias o semejanzas que finalmente pudieran existir con los directores legítimamente nombrados, consideramos que será más sencillo para el juzgador, analizar o determinar quienes pueden ser considerados como un director encubierto.

Esto redunda a favor de la figura en tanto la norma se explaya más en la misma, permitiendo un entendimiento más sencillo de esta, debiendo además notarse, desde que los legisladores han previsto para la figura-como hemos mencionado- una sección diferenciada, que existe cierta recurrencia de casos y situaciones que ha hecho necesaria su previsión.

Asimismo, se puede notar, con relación a la Companies Act 1985 una evolución normativa pues el numeral (3) de la Sección 251 de la Companies Act 2006 señala en qué casos no nos encontramos ante la figura del director

93 Companies Act 2006

"251 "Shadow alrector"

(1) In the Companies Acts "shadow director", in retation to a company, means a person in accordance with whose direc" tions or instructions the directors of the company are accustomed to act.

(2) A person is not to be regarded as a shadow director by reason only that the directors act on advice given by him in a professional capacily.

(3) A body corporate is not to be regarded as a shadow director of any of its subsidiary companies for the purposes of Chapter 2 (general duties of directors).

Chapter 4 (transactions requiring members' approval), or

Chapter 6 (contract with sole member who is also a director), by reason only that the directors of the subsidiary are accustomed to act in accordance with its directions or instructions". 
encubierto, que es cuando básicamente existe una relación matriz subsidiaria, situación que no se encontraba claramente regulada en la Companies Act 1985 y que dio lugar a varios procedimientos judiciales.

Por otro lado, la Sección 251 de la Companies Act 2006 lo que no previene, a diferencia de la Sección 741 de la Companies Act 1985, es qué supuestos correspondientes a directores serán aplicables a un director encubierto, dejando dicha función a otras secciones de la Companies Act 2006. Por lo que nos encontra* mos ante una norma que lo único que busca es delinear los alcances de la figura del director encubierto no señalando los supuestos de aplicación.

94 Companies Act 2006.

" 187 Dectaration of interest in existing transaction by shadow director read at meeting of diretors) does not apply.

95 Companies Act 2006

(1)For the purposes of-

(a) sections 188 and 189 (directors' service contracts).

(b) sections 190 to 196 (property transactions).

(c) sections 197 to 214 (loans etc), and status as a shadow director".

96. Companies Act 2006

"227. Director's service contracts a subsidiary of the company, or ble by a third party to the company, or to a subsidiary of the company. director of a company.
Dichos supuestos son senalados taxativamente por: Sección 187: Declaración de interés personal del director encubierto sobre las transacciones que realice la sociedad. ${ }^{\text {44 }}$

Sección 223: Operaciones de la sociedad que requieren la aprobacion de los directores lcomo es el caso de préstamos y transacciones sobre inmuebles). ${ }^{25}$

Secciones 227 y 230: Son de aplicación a los Directores Encubiertos las provisiones aplicables a los directores de las sociedades, en cuanto a sus contratos de servicios para con estas. ${ }^{96}$

Sección 854: Deber de presentar al registrador, los datos relevantes de la sociedad. ${ }^{37}$

The provisions of this chapter relating to the duty under section 182 dduty to dectare interest in existing transaction or arrangement apply to a shadow director as to a director, but with the following adaptations.

Subsection (2)(a) of that section (declaration at meeting of directors) does not apply.

In section 185 (general notice treated as sufficient declaration), subsection (4) (notice to be given at or brought up and

Generat notice by a shadow director is not effective unless given by notice in writing in accordance with section 184 ".

"223 Transactions tequiring members' approval: application of provisions to shadow directors

(d) sections 215 to 222 (payments for loss of office), a shadow director is treated as a difector.

(2) Any reference in those provisions to loss of office as a director does not apply in relation to loss of a person's

(1) For the purposes of this Pat a director's "service confract" in relation to a company means a controct under which(a) a director of the company undertakes personally to perform services (as director or atherwise) for the company, or for

(b) services (as director or otherwise) that a director of the company undertakes personally to perform are made availaw

(2) The provisions of this Part relating to directors' service contracts apply to the terms of a person's appointment as a

They are nol restricted to contracts for the performance of services outside the scope of the ordinary duties of o director". Companies Act 2006

"230 Directors" service contracts: application of provisions to shadow directors

A shadow director is treated as a director for the purposes of the provisions of this Chapter".

97 Conpanies Act 2006

"854 Duty to deliver annual retums

(1) Every company must deliver to the registrar successive annual retums each of which is made up to a date not later than the date that is from time to time the company's return date.

(2) The company's retum date is- 
Finalmente, de todo lo expuesto podemos concluir que el cambio normativo importa una evolución en la legislación que regula la figura del director encubierto, en tanto le otorga a tal figura su propia Sección, donde se puede observar una definición más clara de la figura asi como de sus excepciones, convirtiendo en más sencilla su interpretación.

\section{EL DIRECTOR ENCUBIERTO EN LA DOCTRINA ROMANO-GERMANICA}

Habiendo analizado ampliamente la figura del director encubierto en cuanto a la normativa, jurisprudencia y doctrina en los países regidos por el Common Law, resulta necesario en este punto analizar hasta que punto la figura del director encubierto ha sido recogida por los paises regidos por el derecho romano-germánico.

Hemos descubierto de distintos modos que la doctrina en idioma español llama al director encubierto como administrador oculto, es por eso que a partir de este punto podremos dew signar a la figura como director encubierto o administrador oculto.

\section{El administrador oculto en la doctrina española}

Es asi que, segùn el Informe Aldama ${ }^{98}$ un elemento decisivo para incrementar la seguridad en los mercados ante las infracciones a los de." beres de lealtad vendria dado por la extensión subjetiva de aquellos deberes cuya naturaleza lo permitan, a quienes, aún sin ostentar una posición formal de administradores (debemos entender que el administrador según la legislación española se podria entender como un símil de director en la legislación peruana), desempeña en la sociedad un papel de indole similar.

El Informe Aldama, justifica la extensión de tal responsabilidad en tanto que las personas que se desempeñan como administradores sin serlo a menudo actuando en la sombra o detrás de los organos de decision formales, determinan una menor eficacia disciplinar por parte de los instrumentos dispuestos por el mercado para sancionarlos. Según el Informe Aldama entre las personas a las que debería alcanzar dicha responsabilidad se encuentran"los administradores ocultos, bajo cuyas instrucciones suelen actuar los administradores de la sociedad"."

Agrega Cándido Paz-Ares que la responsabilidad de los administradores de la sociedad debe ser extendida de manera integral, en este caso en particular, a los administradores ocultos, en tanto que, si actúan practicamente como administradores, normativamente deben responder como administradores, tanto por negligencia como por deslealtad. ${ }^{100}$

Sin perjuicio de ello Paz-Ares va un poco más allá que el Informe Aldama al proponer abiertamente la extensión de los alcances del artículo 134 de la Ley de Sociedades Anónimas ${ }^{101}$ española a los

(a) the anniversary of the company's incorporation, of

(b) if the company's last return delivered in accordance with this Part was made up to a different date, the anniversary of that date.

(3) Each return must.

(a) contain the information required by or under the following provisions of this Part, and

(b) be delivered to the registrar within 28 days after the dote to which it is made up".

98 Informe de la comisión especial para el fomento de la transparencia y seguridad y en las sociedades cotizadas (conocido como el Informe Aldama en honor al presidente de 3 comisión), España, 2003, p. 25.

99 lbid., p. 25.

100 PAZ.ARES, Candido, La responsabilidad de los administradores como instrumento de gobierno corporativo. En: Revista In Dret, Barcelona, 2003, p. 18.

101"Articulo 134, "Accion social de responsabilidad.

1. La acción de fesponsabilidad contra los administradores se entablarả por la sociedad. previo actuerdo de la junta genera, que puede ser adoptado aunque no conste en el orden del día. Los estatutos no podrán establecer una mayoria distinta a la prevista por el articulo 93 para la adopción de este acuerdo. 
administradores ocultos, definiendo aquellos como"(. . ) la persona bajo cuyas instrucciones estén acostumbrados a actuar los administradores de lo sociedad".102 Sin embargo, señala que este requiere una modificación técnica pero no en sustancia. ${ }^{103}$

Con relación al planteamiento del common law, el planteamiento hecho por el informe Aldama y Paz-Ares difieren en un elemento sustancial. Dicho elemento es que el common low solo extiende a los directores ocultos cier. tas responsabilidades de los directores de la sociedad, mientras que la doctrina española está optando por extender la totalidad de tales responsabilidades.

Por otro lado, Alvaro Espinós Borrás de Quadras señala que la falta de definción legal de lo que debe entenderse como un administrador de hecho permite desarrollar una actividad integradora, contemplando como posibles casos de administración fáctica a los administradores ocultos ${ }^{104}$, extendiendoseles la totalidad de las responsabilidades de los administradores de la sociedad. Ante tal conclusion debemos señalar que entender que el administrador oculto ejerce una administración de hecho de la sociedad no es del todo exacto, consideramos más bien que el administrador oculto ejerce una administración a través de terceros en tanto entendemos que el administrador oculto influencia a los terceros con poder de decisión en la sociedad, mas no dirige a esta de manera directa, generando efectos de manera indirecta, efectos que entendemos no quiere o no puede generar de manera directa.

Finalmente, consideramos que la doctrina y en particular la española dispone de los instrumentos conceptuales suficientes que le permitiràn dibujar con mayor claridad y precision el perimetro de tales responsabilidades, por lo que, no intentando juzgar al autor, creemos que la extensión pura y simple de tales responsabilidades no es quizás el mejor camino normativo. Sin embargo, reiteramos que no nos atrevemos a juzgar posiciones en tanto que la elección de una posicion doctrinaria, como en este caso se hace con relacion a la figura del director encubierto (figura heredada por parte del common law), responde a factores distintos a los que originalmente se plantearan cuando esta figura se creó, mas aun teniendo en consideración que tal figura es de reciente anàlisis en profundidad por parte de la doctrina romano-germánica. ${ }^{\text {105 }}$

2. En cualquier momento la junta general podrà transigir o rentunciar al ejercicio de la accion, siempre que no se opusieren a ello socios que representen el cinco por ciento del capital social.

El acuerdo de promover la acción o de transigi determinarála destitución de los administradores afectados.

3. La aprobación de las ruentas anuales no impedirá el ejercicio de la acción de responsabilidad ni supondrá la renuncia a la acción acordada o ejercitada.

4. Los accionistas, en los terminos previstos en el articulo 100 , podrán solicitar la convocatoria de la junta general para que esta decida sobre el ejercicio de la acción de responsabilidad y tambièn entablar conjuntamente la acción de responsabiliciad en defensa del interés social cuando los administradores no convocasen la junta generat solicitada a tal fin, cuando la sociedad no la entablare dentro del plaze de un mes, contado desde la fecha de adopcion del correspondiente acuerdo, o bien cuando éste hubiere sido contrario a la exiçencia de responsabilidad.

5. Los acreedores de la sociedad podian ejercital la acción social de responsabilidad contra los administradores cuando no haya sido ejercitada por la sociedad o sus accionistas, slempre que el patrimonio social resulte insuficiente paza la satisfacción de sus créditos".

102 PAZ-ARES, Candido, Op. Cit, p. 49

l03Mail enviado por el Doctor Cántido Paz-Ares al autor de este trabajo con fecha 08 de noviembre de 2007 : La figura del director oculto está englobada en la noción más amplia de "administrador de hecho" que contempla el afticulo 134 de la LSA española. Mi secretaria le enviará un papel mio en el que se contienen algunas reterencias bibliograficas que pueden serle de utilidad. Un cortial saluto, Candido Paz Ares.

104 ESPINOS BORRAS DE QUADRAS, Alvaro, La responsabildad en las sociedodes mercantiles, Madrid. Noticias Juridicas, 2005, p. 7 .

1OS Asimismo, queriamos resaltar que ya en 1985, Jesús Quijano Gonzalez sen̆alaba que, a su parecer, la resmonsabilidad de los directores de hecho surgiria no solo en los casos en que aquellos hubiefan sustituido efectivamente a los dizecrores, sino tambièn si se acredita que han influido en forma determinante sobre ellos en la toma de decisiones. LQUUANO GONZÁLEZ, Jesús, La responsabitidad civil de los odministradores de la sociedad anónima, valadolid, $1985, \mathrm{p} .331$ ). 


\section{Eladministrador oculto o director encubierto en la doctrina latinoamericana}

Como se desprende de lo expuesto en el numeral precedente la doctrina española aùn no es uní" voca en el tema de los directores encubiertos y el desarrollo de la misma todavia no ha alcanzado la madurez necesaria para convertirse en norma positiva requiriendo aún de mucho mas debate.

Teniendo en consideracion to expuesto en el párrafo anterior hemos tambièn buscado resquicios de la figura en otras jurisdicciones encontrando algunas menciones en el derecho uruguayo y en el colombiano, sin embargo, ambos acercamientos a la figura del director encubierto aún son muy tenues.

Así, la doctrina uruguaya a travès de Nuri Rodríguez Olivera nos enseña que en tanto existen directores ocultos en una sociedad se les debe extender el régimen de responsabilidad de los directores. ${ }^{106}$

Continúa señalando la autora que, por ejemplo, en el caso de situaciones de grupo empresarial, donde la controlante designa a lós directores de las controladas deberá hacerse extensiva la responsabilidad de los directores de las controladas a la designante.

Por otro lado, se hace relevante citar jurisprudencia suiza del año 1981 la cual señala que" (...) los representantes de la Societé de Banque Suisse tenian una gran influencia sobre la sociedad y contribuian activamente a la formación de la voluntad social, abreviando, ellos eran material. mente los organos de la sociedad". ${ }^{107}$

El trabajo realizado por Rodriguez resulta relevante en tanto que hace referencia a doctrina distinta a la de common low, de una antigüedad un poco mayor al Companies Act 1985, doctrina que es de una claridad abrumadora. Es iniportänte además dado que demuestra un trabajo avanzado en la materia en jurisdicciones europeas distintas a las del common lawy distintas a la española.

Sin perjuicio de lo explicado párrafos arriba, el autor colombiano Camilo Enrique Cubillos Garzón no es tan osado, pues no realiza aná lisis propio senalando que "(...) en el derecho del common law el régimen de responsabilidad era propio de la sociedad y no cabia extenderlo a terceros (...) sin embargo esta posicion con el tiempo fue variando hasta contemplar la posibilidad de aceptar la responsabilidad de terceros en dos eventualidades, con relacion a los socios la doctrina del "disregard of legalentity o piercing of corporate vail" y la segunda con relación a terceros a su vez de dos tipos: (i) de gestores conocidos como tales pero que no se encuentran investidos legalmente-gestor de hecho-(de facto director); o (ii) de administradores que no se presentan frente a terceros pero siactúan como tales-administradores ocultos- (shadow director)"

Finalmente, podemos concluir que en cuanto a Latinoamèrica, si bien existe un acercamiento hacia la figura del director encubierto, este acercamiento aún es muy tenue y tangencial y se mantiene unicamente a nivel doctrinario.

\section{El director encubierto en la regulación peruana}

Como hemos explicado en su oportunidad, la figura del director encubierto no está contemplada en la regulación peruana, como sí lo están la figura del director suplente y el director alterno ${ }^{109}$, claramente señaladas por el doctor

106 RODRGGUZ OLIVERA, Nưi, Extenslón de responsabilidad en conjuntos económicos, Editorial del foro, Montevideo, $2002, p 32$.

107 tbid., p. 37.

108 CUBILLOS GARZON, Camilo Enrique, Crisis empresariol al interior de un grupo de sociedodes. En: Revista e Mercatoria, Volumen 4, No. 2. Universidad Externado de Colombla, Bogotá, 2005. p. 38

109 Ley General de Sociedades:

"Articulo 153.+ Organo colegiado y election

El directorio es órgano colegiado elegido por la junta general. Cuando una o más clases de acciones tengon derecho $\sigma$ elegir un determinado número de directores, la eleccion de dichos directores se hara en junta especial. 
Oswaldo Hundskopf Exebio en la entrevista que le realizáramos en su oportunidad. "1:

Estos procesos donde se señala la responsabilidad de una persona como director encubierto, tienen por lo general una característica en común, salen a la Juz, consecuencia de procesos de insolvencia y liquidación.

Es importante tener en claro además que en el Perú existe una clara tendencia para llevar los procedimientos de insolvencia y de quiebra en la via administrativa a través del Instituto Nacional de Defensa de la Competencia y de la protección de la Propiedad Intelectual (en adelante, "NDECOP1"),"1" cosa que en la mayoria de jurisdicciones mas aún en las del commonlaw se hace en la via judicial (inglaterra, Australia, Nueva Zelanda, Malasia, Singapur, entre otros).

Finalmente, consideramos que queda demostrado que en el supuesto que se desea im. plementar la figura del director encubierto se deberá modificar normativa adicional a la Ley General de Sociedades.

\section{COMPARACIÓN ENTRE LA REGULACIÓN PARA DIRECTORES QUE APLICA PARA LOS OIRECTORES ENCUBIERTOS EN EL COMMON LAW Y LAS RESPONSABILIOA- OES BAJO LEY GENERAL OE SOCIEADES APLICABLES A LOS OIRECTORES}

Las semejanzas a las que nos referiremos a continuacion unicamente se refieren a aquellas disposiciones que, sobre directores, rigen tambièn para directores encubiertos, segun la Companies Act inglesa de 1985 y a la que antes nos hemos referido.
Nos basaremos en la norma antes mencionada, por cuanto consideramos que la misma, al ser la pionera en regular y reconocer la figura del director encubierto, es tambièn la que regula con mayor eficiencia los supuestos en los cuales tal figura, de ser detectada, determinarà la responsabilidad de la persona que ejerce el cargo.

En relación a la Sección 320 transacciones significativas de propiedad que involucren directores), en su texto encontramos las siguientes condiciones que nos permiten cierto paralelo con algunos articulos de la Ley General de Sociedades:

(a) Se requiere un valor minimo para la trans ferencia, debiendo recordarse que si bien nuestra legislación no exige el mismo, en el caso de transferencia de activos, si el valor contable supera el $50 \%$ del valor del capital social, ${ }^{1 ; 2}$ tal transferencia debe ser aprobada por la Junta General de Accionistas.

Debe recordarse que pesa sobre el directorio la responsabilidad de formular la memoria anual y los estados financieros, asi como su deber primordial de vigilar la marcha social, sin embargo, siendo la junta general de accionistas el organo social supremo, recae sobre esta la facultad y responsabilidad de autorizar un acto de tal naturaleza, pues este podría desfinanciar a la sociedad o volver su marcha inestable.

(b) Asimismo, la normativa inglesa provee inteligentemente de ciertos parämetros de valorización de activos de los cuales nuestra norma carece y que son importantes para la determinación de cuàndo una transacción

110 Entrevista al doctor Oswaido Hundskopf Exebio, donde este señala:

"Actualmente en nuestra Ley General de Sociedades no esta contemplada la figura del director encubierto Siendo figuras distintas, se contemplan tos directores altemos o suplentes, en miopinion sin embargo es un tema te gran importancio y seria recomendable que exista una regulacion de esta figura (....".

Il A traves de la ley que lo faculta para eso, la "Ley General del Sistema Concursal; Ley 27809 ".

112 "Articulo 115 de la Ley General de Sociedades.

Otras atributiones de la Junta:

Compete, asimismo, la Junta General

(...)

5. Acordar la entenación, en un solo acto, de activos cuyo valor contable exceda el $50 \%$ del capital social". 
se convierte en significativa y, por lo tanto, al involucrar a los directores, cobra aún más importancia,

Nuestra referencia más cercana en la nor" mativa peruana es el artículo 76 de la Ley General de Sociedades, que deja la revisión de la valorización (en los casos de aportes no dinerarios) a los directores $y$, en caso algùn accionista se encuentre en desacuerdo con la misma, a la determinación pericial solicitada mediante el proceso abreviado, siendo la sanción en el caso de subvaluación para el accionista aportante.

(c) Como tercer supuesto, la ley inglesa se refiere obviamente a los casos en que las transacciones sean efectuadas con un director de la sociedad, de una sociedad relacionada con la sociedad o una persona relacionada con dicho director.

Nuestra legislación prevé en su artículo 180 los casos de conflicto de intereses, sin embargo no se detiene a extender el supuesto a directores de otras sociedades relacionadas, pero si a terceros relacionados, entendién. dose del texto que se trataría de terceros relacionados con el director en cuestión.

En relación a la sección 322 (Incumplimientos a la sección 320), nuevamente la misma mantie-" ne ciertos presupuestos importantes que son semejantes a los establecidos por la legislación peruana:

(a) El acuerdo celebrado por la compañia puede ser anulable, salvo que sea ratificado por la junta general de accionistas. Nuevamente existe cierta similitud con nuestra legislación, la que en su articulo 179, señala que los directores solo pueden celebrar operaciones que versen sobre aquellas que la empresa normalmente realice, al igual que la sociedad solo les puede conceder créditos u otorgarles garantias en las mismas condiciones. De no reunir la transacción tales elementos, será necesario que previamente el directorio (no la jun ta general como en el caso inglés), autorice la misma. (b) El director no será responsable si demuestra que adoptó todas las precauciones razonables para asegurar que la empresa cumpla con las disposiciones legales.

En nuestro caso, los directores según los artículos 178 y 179 de la Ley General de Sociedades son responsables en los casos en que se celebren contratos o se otorguen prèstamos o garantias con infracción pero no serán responsabilizados de los actos irregulares si dejaron su disconformidad con el mismo, sea en la misma acta o por carta notarial.

Asimismo, con relación a la sección 330 (Restricciones generales a créditos y otros con directores y personas relacionadas con ellos), consideramos que esta mantiene una similitud importante con el articulo 179 de nuestra Ley General de Sociedades, en tanto restringe el otorgamiento de préstamos y garantias a directores y personas relacionadas con estos.

Por otro lado, la sección 335 (transacciones menores y de negocios) prevé, al igual que nuestro ordenamiento en su artículo 179 , que no se encuentran prohibidos los acuerdos que involucren directores, si tales acuerdos son ordinariamente celebrados por la sociedad, debiendo resaltarse que los tèrminos en lo que se lleve a cabo la transacción no deberàn ser más favorables que aquellos que la sociedad normalmente acordaria un terceros no relacionado.

Con relacion a la sección 337 (financiamiento de los gastos del director en ejercicio de su cargo en nombre de la sociedad), la referencia más cercana pero no necesariamente exacta, la encontramos en el artículo 24 de la Ley General de Sociedades, la cual confiere a los directores la facultad de efectuar gastos necesarios para la sociedad, bajo su responsabilidad.

Los gastos de representación en nuestra legislación se encuentra regulados por el Texto Único Ordenado de la Ley del Impuesto a la Renta, aprobado por Decreto Supremo No. 179-2004EF (y normas modificatorias y ampliatorias). artículo 37, literal (q), y por el Reglamento de la

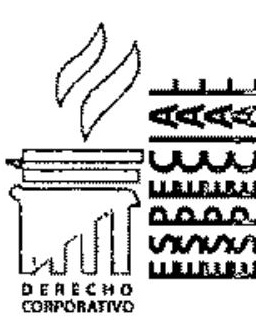


Ley de Impuesto a la Renta, Decreto Supremo No. 122-94-EF, artículo 21, que señalan que los gastos de representación propios del giro del negocio que, en conjunto, no excedan del $0.5 \%$ de los ingresos brutos, con un límite máximo de cuarenta unidades impositivas tributarias seràn deducibles.

Se consideran gastos de representacion propios del giro del negocio a: (i) los efectuados por la empresa con el fin de ser representada fuera de sus oficinas, locales o establecimientos; y (ii) los gastos destinados a presentar una imagen que le permita mantener o mejorar su posición de mercado, incluyendo obsequios y agasajos a clientes, no encontrándose comprendidos en tal concepto a los gastos de viaje y erogaciones dirigida a la masa de consumidores reales o potenciales, como los gastos de propaganda.

La aplicación de la responsabilidad civil y penal establecidas en las secciones 341 y 342 de la Companies Act 1985, differen diametralmente de nuestra legislación, la cual en sus articulos $7,18,24,40,62,177,424$ y en la Segunda Disposicion Transitoria de la Ley General de Sociedades, señala que ante el incumplimiento de los supuesto especificados en los mismos, el director tiene responsabilidad civil, mientras que en los articulo 12 y 424 indica los supuestos de responsabilidad penal.

La Companies Act 1985, cuyo texto acompañamos, indica expresamente los supuestos de responsabilidad civil, senalando que el caso de la responsabilidad penal que esta sera tratada como una falta.

"341. Responsabilidad civil porincumplimiento de la seccion 330:

(1) Si una compañia celebra una transaccion o acuerdo en contravención de la sección $330,1 a$ transacción o acuerdo es anulable, a solicitud de la sociedad, salvo que -

(a) La restitucion de cualquier dinero $u$ otro activo materia del acuerdo o transaccion yano sea posible, ola compañia haya sido indemnizada en cumplimiento con esta sección por otra persona por la perdida o doño sufrido por la misma; o

(b) El derecho fue adquirido de buena fe a su valor y no media notificacion de contravención al acuerdo por una persona que no forma parte del mismo que pudiera causar la anulabilidad del convenio;

(2) Donde el acuerdo o transacción es efectuado por la sociedad, para un director de la compañia o de su sociedad holding o para una persona relacionada con dicho director en contravención a la seccion 330 , tal director y la persona a el relacionada y cualquier otro director de la compañia que autorizó la transaccion o acuerdo laun cuando haya sido anulado en cumplimiento de la seccion (I) es responsable de:

(a) reportar a la compan̈ia cualquierganancia que hayaobtenido directao indirectamente por el acuerdo o transaccion; y

(b) (en conjunto y por separado con cualquier otra persona responsable bajo esta subsección) de indemnizar a la compañia por cualquier perdida o daño que resulte del acuerdo o transacción.

(3) La subseccion (2) se impone sin perjuicio de cualquier responsabilidad generada por esa subsección, estando sujeta además a las dos siguientes subsecciones.

(4) Donde un acuerdo o transaccion es realizado por una sociedad y una persona relacionada con el director de la sociedad o de su sociedad holding en contravencion a la seccion 330 , tal director no es responsable segun la subsección (2) de esta sección, si demuestra que siguió todos los pasos razonables para asegurar el cumplimiento de la sociedad con tal seccion.

(5) En cualquier caso, una persona asi relacionada y cualquier director como se menciona en la subsección (2) no seran responsables si demuestran que, al momento de celebrarse el acuerdo o transaccion, desconocian las circunstancias relevantes que constituyen la controvención". 
342. Responsabilidad penal por incumplimiento de la sección 330 :

(1) Un director de una sociedad listada que autorice o permita la participación de esta en una transacción o acuerdo sabiendo o teniendo causas razonables para creer que la sociedad estaba contraviniendo la sección 330 es culpa ble de una falta.

(2) Una sociedad listada que participa en una transacción o acuerdo para uno de sus directores o para un director de su sociedad holding en contravencion de la sección 330 es culpable de una falta.

(3) Una persona que procura que una sociedad listada celebre una transacción o acuerdo sabiendo o teniendo causa razonable para creer que estaestaba contraviniendo la sección 330 es culpable de una falta.

(4) Una persona culpable de falta segun los tèrminos de esta sección puede ser sancionada con encarcelamiento o multa, o ambos.

(5) Una sociedad listada no es culpable de faita según la subsección (2) si demuestra que, al momento de celebrarse la transaccion o acuerdo, no conocia las circunstancias relevantes."113

Asimismo, la Companies Act 1985 hace referencia en su disposición 345 (poder para incrementar los limites financieros), a la posibilidad que el Secretario de Estado sustituya los limites minimos de dinero establecidos, por sumas mayores.

Una disposición similar la encontramos en el numeral 8 del artículo 200, de la Ley General de Instituciones Bancarias, Financieras y de Seguros y Orgánica de la Superintendencia de Banca y Seguros que, al referirse a los límites globales por operación, indica que la Superinm tendencia de Banca, Seguros y Administradoras de Fondos de Pensiones puede establecer otros (no incrementar) límites globales, por razones prudenciales, previa opinión del Banco Central de Reserva.
Asi, la sección 346 de la Companies Act 1985 se refiere a las personas que se consideran relacionadas con un director, incluyendo la esposa, hijo, hijastro, incluyendo el caso de fideicomisos que los beneficiaràn.

Por otro lado, nuestra normativa incluye en el articulo 179 de la Ley General de Sociedades, referencias, en el caso de contratos a ser celem brados con directores o créditos y garantías a ser otorgados a estos, que las disposiciones que para tales transacciones prevé la ley alcanzan a los directores de empresas vinculadas, conyuges, descendientes, ascendientes y parientes dentro del tercer grado de consanguinidad o segundo de afinidad de los directores de la sociedad y de los directores de las empresas vinculadas, debiendo recordarse los criterios de vinculación aprobados por el Reglamento de Propiedad Indirecta, Vinculación y Grupos Económicos aprobado por Resolución de la Comision Nacional Supervisora de Empresas y Valores No. 090m2005-EF/94.10.

Finalmente, hemos de indicar que entre la legislación inglesa y la legislación contenida en la Ley General de Sociedad no existe realmente una raiz comun en cuanto a la regulación de la responsabilidad de los directores, mas aun con relación a aquella que regula a los directores encubiertos. Simplemente ambas se basan en los deberes fiduciarios de carácter general regulados en ambas normas, deberes fiduciarios sobre los cuales se han ido construyendo regulaciones distintas (sin perjuicio que puedan ser conceptualmente similares).

\section{XIII.CONCLUSIONES}

1. De acuerdo al análisis realizado en este trabajo, el director encubierto es aquella persona natural o jurídica que brinda instrucciones tácitas y/o expresas a uno y más directores. Este hecho permite al director encubierto actuar como órgano social y, en consecuencia, recibir, en cuanto le sea aplicable, el trato de director de una sociedad.

113 Companies Act 1985 . 
Por otro lado, es preciso señalar que una socledad no puede ser tratada como director encubierto de ninguna de sus sociedades subsidiarias únicamente porque los directores de la sociedad subsidiaria esten acostumbrados a actuar en concordancia con sus direcciones o instrucciones. En el mismo sentido, una persona no podrá ser señalada como director encubierto solo porque la mayoría del directorio de una sociedad haya actuado bajo sus consejos, en concordancia con la capacidad profesional de tal persona.

2. Puede decirse que, en términos generales, el director encubierto es una figura alun incj... piente. Si bien existen algunas referencias a esta figura en la doctrina romano-germánica, el desarrollo central de esta figura se ha pro* ducido en el ambito del common law.

3. En el Common Law, la figura del director encubierto ha sido materia de regulación en la normativa societaria (Companies Law) de Inglaterra, Irlanda, Australia, Nueva Zelanda y Singapur. La interpretacion de los alcances de la regulación aplicable a los directores encubiertos, sin embargo, aun es materia de debate jurisdiccional. Ello porque la normativa no es taxativa, sino mas bien enunciativa. Es decir, si bien define formalmente las caracteristicas de un director de una sociedad, deja la posibilidad de que existan otras formas de ejercer dichas funciones.

Este hecho, en si mismo, permitió el desa" rrollo de la figura del director encubierto en diversas cortes de justicia. La jurisprudencia ha establecido los siguientes principios:

- Los directores encubiertos pueden ser personas naturales o juridicas (sin perjuicio que en jurisdicciones como la austra liana o la peruana los directores de jure solo pueden ser personas naturales).

- Es innecesario establecer que en efecto las direcciones o instrucciones fueron comunicadas de forma expresa al direc- torio de una sociedad. Sin embargo, debe establecersela intención del supuesto director encubierto de ejercer control sobre la mayoria de los miembros del alegado directorio.

* En la jurisdicción australiana y neozelandesa no queda claro si todos o solo la mayoria de los directores, deben actuar en concordancia con las direcciones o instrucciones comunicadas por el supues to director encubierto. Sin embargo, se sugiere, aun en tales jurisdicciones, que requerir la totalidad de directores del directorio, sería ignorar y desnaturalizar el proposito de la regulación en la materia. Interpretar que la totalidad de los directores deben estar bajo el control del antes mencionado director encubierto implicaria un vacio en la regulación.

- El hecho que los directores de una sociedad ejerzan cierta discreción decisoria en el manejo de una sociedad no inhibe la existencia de un director encubierto en tal sociedad.

Los alcances de la palabra "consejo" differen sustancialmente de los alcances de las palabras "direcciones o instrucciones". El hecho que los directores de una sociedad puedan seguir los consejos de un tercero en cierta materia puntual, no implica necesariamente que tal tercero se vaya a constituir en director encubierto de tal sociedad.

4. Actuar como director encubierto no es un delito ni una talta en si misma (salvo que, por ejemplo, en el caso de inglaterra, la persona que actua como tal, haya sido descalificada bajo los alcances de, por ejemplo, la Company Directors Disqualification Act 1986 para ejercer el cargo de director o se le haya declarado quebrado).

Por último, una sentencia del tribunal de primera instancia de Londres, confirmado por la corte de apelaciones de inglaterra, ha establecido una distinción entre directores 
de jure, de facto y encubierto (Uitraframe (UK) l.td. vs. Fielding and others (2005)),

5. La regulación del director encubierto, se enmarca dentro del ámbito de protección que la jurisprudencia del common law tiene respecto de accionistas, acreedores y terceros interesados. Es decir, se busca que el director encubierto, en ciertos supuestos, se sujete a los deberes fiduciarios aplicables a los directores de jure. Ello porque la regu" lación aplicable a los directores encubiertos se base en la extensión de dichos deberes genéricos de lealtad y diligencia. A su vez, la aplicación de deberes fiduciarios a los difectores encubiertos tiene como consecuencias extender la responsabilidad frente a la sociedad, acreedores y terceros, a todas aquellas personas que intervengan en la administracion o la toma de decisiones de una sociedad.

En el mismo sentido, la aplicación de las sanciones al director encubierto se deriva de los principios de responsabilidad que atañen a los directores de una sociedad al no cumplir con alguna obligacion legal o estatutaria. Es decir, si una persona actúa como director de la sociedad no sièndolo, debería encontrarse sujeta a, cuando menos, algunas responsabilidades de un director debidamente nom. brado, asi como a las sanciones aplicables a estos.

6. Es importante asegurar que individuos que no son directores de jure de una sociedad, pero que influencian la manera en la que los asuntos de una sociedad son manejados, respondan por su responsabilidad de mane. ra adecuada. Asimismo, este tema, no puede ser pasado por alto, particularmente en empresas que listan en mecanismos centralizados de negociación, donde la transparencia es absolutamente esencial.
Este punto es resaltado de mejor manera por el tratadista Kim Howells quien señaló para el caso 'Trade and Industry v Deverell que "ampliando la definición de director en. cubierto el público en general adquirira una mayor protección y tranquilidad al saber que si una persona se inmiscuye en el manejo de una sociedad de manera ilicita, tenemos la posibilidad de traerlo a la luz".114

7. No obstante el director encubierto ha sido, fundamentalmente, materia de análisis en el common law, la relevancia de esta figura se verifica en el ámbito empresarial. En ese sentido, la mayoría de los entrevistados durante la realizacion de este trabajo señalaron que, en mayor o menor medida, habian percibido la influencia de terceros durante su gestión. Este hecho, permite concluir que hay necesidad de implementarla, no obstante ello, hay opiniones encontradas, las cuales señalan, en términos generales, que la capacidad de implementar y ejecutar medidas de relativas al gobierno corporativo en el Perú es muy baja, en esa línea de pensamiento la regulación del director encubierto resulta muy compleja y dificil de implementar. En ese sentido, los miembros de comisión que redacto el proyecto de la Ley General de Sociedades señalaron que si bien su regulación es valida optan por señalar que es importante primero reforzar la regulación que se tiene en la materia, así como la supervisión de la misma, antes de incursionar en figuras jurídicas aplicables a regulaciones societarias mas avanzadas.

8. Siendo que la figura del di rector encubierto está basada en los principios de responsaw bilidad general aplicable a los directores, principios de responsabilidad general que se encuentran reconocidos tambien en la normativa del Perú, entonces, teóricamente, sería posible aplicar esta figura en el Perú y

144 Jurisdiccion de inglaterra: [2000] ER 365 in 2000.

"(...) by broadening the definition of Shadow Directors, the public will get greater protection, and more peact of mind that if someone has been evolved in running a company in on unfit way, we have the ability to bring them to book". 
sustentándose en ella los juzgadores podrian sancionar a aquellas personas que calcen dentro de la figura del director encubierto tal y como esta figura ha sido analizada en la presente tesis.

Sin embargo, a lo largo de esta tesis hemos podido apreciar que la figura del director encubierto no funciona independientemente del resto de la constelación normativa donde esta se encuentra contenida, pues vemos que se presenta por ejemplo de la mano de figuras como la del director de facto, asi como los supuestos y procedimientos para la descalificación de directores.

Es por esta razón que, si se implementara la figura del director encubierto de forma independiente, de manera estricta, sin hacerlo de la mano de las demás figuras relacionadas, esta perderia efectividad y se desarrollaría de manera poco idonea en nuestro ordenamiento, lo que causaria más problemas que soluciones, al ocasionar vacios legales. Volviendose inaplicable en la pràctica.

Vaclos que consideramos que no podrian ser solucionados usando los principios generales del derecho, mucho menos aun del derecho peruano, asi como se encuentra este regulado en el numeral (3) del Artículo 184 del Decreto Supremo No. 017-93-JU5:"Texto Unico Ordenado de la Ley Orgánica del Poder Judicial:"115

Por lo que nos mostramos cautelosos en su implementación sin más estudio que este.

115 Texto Unico Ordenado de la Ley Orgánica del Poder Judicial.

"Articulo 184.- Son deberes de los Magistrados.

(...)

3.- A falta de norma jurdica pertinente, las Aagistrados deben resolver apticando los principios generates det Derecho y preferentemente tos que inspiran el Derecho Peruano; $(. . .)^{n}$. 